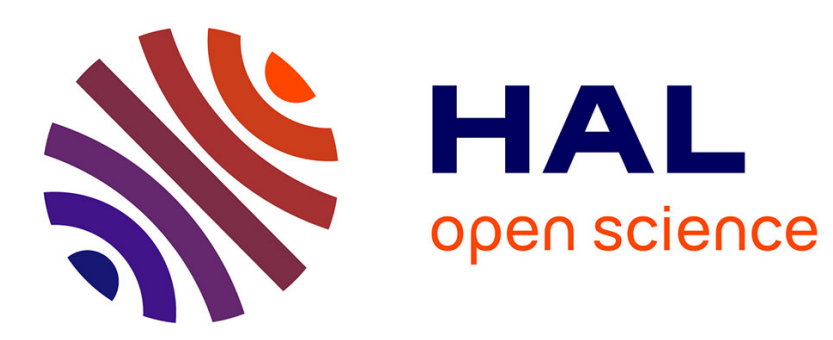

\title{
Analysis of mixture structure and of its influence on combustion in a CAI engine \\ Vincent Knop
}

\section{To cite this version:}

Vincent Knop. Analysis of mixture structure and of its influence on combustion in a CAI engine. International Journal of Engine Research, 2018, 19 (4), pp.393-410. 10.1177/1468087417712160 . hal-01978548

\section{HAL Id: hal-01978548 \\ https://hal-ifp.archives-ouvertes.fr/hal-01978548}

Submitted on 11 Jan 2019

HAL is a multi-disciplinary open access archive for the deposit and dissemination of scientific research documents, whether they are published or not. The documents may come from teaching and research institutions in France or abroad, or from public or private research centers.
L'archive ouverte pluridisciplinaire HAL, est destinée au dépôt et à la diffusion de documents scientifiques de niveau recherche, publiés ou non, émanant des établissements d'enseignement et de recherche français ou étrangers, des laboratoires publics ou privés. 


\title{
Analysis of mixture structure and of its influence on combustion in a CAl engine
}

Vincent Knop ${ }^{1}$

\begin{abstract}
Homogeneous Charge Compression Ignition $(\mathrm{HCCl})$ combustion mode theoretically relies on a perfectly homogeneous air/fuel mixture simultaneously releasing heat across the whole combustion chamber. However, practical implementation always leads to a staged combustion process that is still significantly quicker than conventional sparkignition or compression-ignition combustion modes. The degree of combustion staging is central to the limitation of combustion-induced noise, to cycle efficiency, as well as to combustion stability and completion. The present study numerically explored on the whole operating map the mixture structure at ignition for a specific type of $\mathrm{HCCl}$ combustion, namely the Controlled Auto-Ignition (CAI) combustion mode attained through burnt gas trapping with negative valve overlap. The analysis of the complete CAI operating map outlined the similarity of mixture structure for any operating condition and the mixture/chemistry interactions depending on the end-of-compression temperature domain. Temperature stratification appeared as the key input defining combustion-induced noise and combustion stability but mean in-cylinder temperature and dilution combine with temperature stratification to define operating map limitations.
\end{abstract}

\section{Keywords}

Controlled Auto-Ignition, Homogeneous Compression Charge Ignition, Mixture stratification, Fuel kinetics, 3D CFD

\section{Acronyms}

$\begin{array}{ll}\text { bTDC } & \text { before Top Dead Centre } \\ \text { CAI } & \text { Controlled Auto-Ignition } \\ \text { CFD } & \text { Computational Fluid Dynamics } \\ \text { CPU } & \text { Central Processing Unit } \\ \text { DI } & \text { Direct Injection } \\ \text { EGRB } & \text { Exhaust Gas Re-Breathing } \\ \text { FAER } & \text { Fuel/Air Equivalence Ratio } \\ \text { HCCI } & \text { Homogeneous Charge Compression Ignition } \\ \text { MON } & \text { Motor Octane Number } \\ \text { MPI } & \text { Message Passing Interface } \\ \text { NVO } & \text { Negative Valve Overlap } \\ \text { NTC } & \text { Negative Temperature Coefficient } \\ \text { PFI } & \text { Port Fuel Injection } \\ \text { PTC } & \text { Positive Temperature Coefficient } \\ \text { RANS } & \text { Reynolds-Averaged Navier-Stokes } \\ \text { RNG } & \text { Re-Normalisation Group } \\ \text { RON } & \text { Research Octane Number } \\ \text { RPM } & \text { Revolution Per Minute } \\ \text { TKI } & \text { Tabulated Kinetics of Ignition } \\ \text { TRF } & \text { Toluene Reference Fuel }\end{array}$

\section{Introduction}

Although Homogeneous Charge Compression Ignition (HCCI) name presupposes a perfect mixture homogeneity, it is today commonly acknowledged that some degree of mixture heterogeneity survives in actual HCCI engines ${ }^{1-8}$.
Published research on mixture heterogeneity quantification generally highlighted the central role of temperature stratification, either as the unique driving force, or as an important quantity competing with others (generally dilution rate and/or mixture strength). Yet, to the best of author's knowledge, previous research works concentrated on isolated operating point(s), so that the variation of the stratification amplitude over a complete HCCI operating map remains unknown. From a numerical point of view (most quantification studies rely at least partly on numerical data), the limitation to isolated operating points relates to the difficulty of accurately describing fuel reactivity over a broad range of conditions within a 3D CFD tool simultaneously predicting the details of species mixing and of gas state evolution.

To expand on existing knowledge and to provide a broader view of mixture stratification influence on HCCI

\footnotetext{
${ }^{1}$ IFP Energies nouvelles, France
}

\section{Corresponding author:}

Vincent Knop, IFP Energies nouvelles, 1 et 4, avenue de Bois-Préau, 92852 Rueil-Malmaison, France; Now at: Cosworth Ltd, The Octagon, Saint James Mill Road, Northampton, NN5 5RA, UK.

Email: vincent.knop@cosworth.com 
combustion mode, present study considered the modelling of multiple operating points across the operating map of a Controlled Auto-Ignition (CAI) engine. CAI combustion mode is a specific realisation of HCCI that relies on burnt gas trapping through valve lift profile alteration and is therefore specifically sensible to mixture stratification. The successful modelling of multiple operating points across the operating map necessitates the combination and refinement of latest methods for fuel reactivity description.

The first hurdle to model actual CAI operation is the selection of gasoline as fuel during most experiments. Since gasoline is not a pure compound but an ever-varying mixture of hundreds of hydrocarbon compounds ${ }^{9}$, there is no preexisting detailed kinetics mechanism for gasoline. The most accurate way to overcome this difficulty is to consider a fuel surrogate, i.e. a mixture of a few compounds having the same key properties as gasoline. In the present study, key properties were auto-ignition properties as well as the fuel lower heating value as local heat release triggers reaction in its neighbourhood. Both sets of properties can be emulated using a ternary mixtures of $n$-heptane, iso-octane and toluene, as demonstrated in ${ }^{9 ; 10}$. The second pitfall is the availability of an accurate kinetics mechanism for the selected surrogate. There are many existing mechanisms for ternary mixtures of $n$-heptane, iso-octane and toluene but the most accurate ones have all already been shown to have limitations when considering CAI combustion mode ${ }^{10}$. In the present study, we confirmed the shortcomings of existing mechanisms and proposed a revision of the iso-octane subset of Andrae's mechanism ${ }^{11}$ to improve the combustion description over the complete operating map. The third difficulty is the resolution of detailed kinetics on a refined grid to provide a precise description of chemistry progress at each local mixture and thermodynamic conditions. For this purpose, detailed kinetics solving was pre-processed through the creation of look-up tables, ensuring an accurate combustion description at a negligible cost during the 3D CFD modelling of intrincate flow motion and reaction.

In the following, known effects of mixture stratification on CAI combustion mode are first described based on a literature review. Then, a short reminder of the method for gasoline surrogate definition and of the detailed chemistry description through tabulation is provided. The reachable CAI operating map for the considered engine is exposed and related conditions for auto-ignition are emphasized. Such conditions are linked to the performances of existing detailed kinetics mechanisms in ideal environments, highlighting some shortcomings. A mechanism revision for iso-octane subset in Andrae's mechanism ${ }^{11}$ is proposed to improve the accuracy of gasoline reactivity prediction in the intermediate temperature domain. The modelling of operating points over the complete operating map demonstrates the accuracy of the combination of approaches (surrogate definition, kinetics description, combustion modelling through tabulation). The analysis of the modelled flow, species and thermodynamic fields provides insights about the influence of operating conditions on in-cylinder stratification and about the relation between mixture stratification, combustion initiation, and combustion progress.

\section{Existing knowledge on mixture stratification in CAl engines}

The analysis of mixture stratification in CAI engines requires either optical diagnostic methods $6 ; 7 ; 12$, or $3 \mathrm{D}$ CFD modelling ${ }^{3-5 ; 7 ; 8 ; 12}$. The numerical approach has the advantage of simultaneously providing insights about all species as well as temperature field, allowing for a combined analysis of the influence of temperature, dilution rate and fuel/air equivalence ratio on combustion initiation and progress. However, gaining confidence into numerical results first requires a detailed validation with optical diagnostic methods $4 ; 5 ; 7 ; 12$.

Babajimopoulos et al. ${ }^{3}$ numerically compared on a single operating point CAI combustion mode obtained through burnt gas trapping with Negative Valve Overlap (NVO) with gasoline HCCI obtained through intake air heating. They were the first to correlate the statistics of temperature and fuel/air equivalence ratio fields with combustion onset, emphasizing the central role of the temperature field. Because of restrictions in the capability of the numerical approach, a direct prediction of combustion within the 3D CFD code was impossible. Babajimopoulos et al. ${ }^{3}$ therefore extracted statistically representative conditions to feed some non-dimensional detailed kinetics computations and, therefore, to study reactivity in various areas of the combustion chamber.

Koopmans et al. ${ }^{4}$ considered a similar numerical approach and also compared gasoline HCCI with NVO CAI combustion mode. Again, no direct coupling existed between mixture solving and kinetics solving but the approach favourably compared to optical diagnostics results in terms of identification of the most reactive regions. Furthermore, Koopmans et al. ${ }^{4}$ emphasized the central role of dilution rate for CAI conditions. They identified a strong correlation between local dilution rate and temperature, which relates to the heating effect of hot trapped burnt gases. The preferential location of burnt gases defines the hottest region and 
therefore the preferential auto-ignition location. For gasoline HCCI conditions, dilution rate was very low and there was no preferential location for highest temperatures, explaining the statistically homogeneous distribution of ignition spots observed during optical diagnostics ${ }^{4}$.

Mori et al. ${ }^{5}$ considered a similar approach to compare two methods to obtain CAI combustion mode: burnt gas trapping through NVO and through Exhaust Gas ReBreathing (EGRB). Mixture stratification appeared larger with EGRB than with NVO which, in turn, induced a larger stratification for temperature with EGRB. The largely stratified mixture numerically observed for the EGRB approach related to highly localised early ignition spots identified with optical diagnostics. On the contrary, the less stratified NVO mixture related to a wider spreading of early ignition spots. Mori et al. ${ }^{5}$ deduced from such observations that mixture stratification directly influenced local heat release even if numerical results could not completely prove it as heat release could not be computed.

Adomeit et al. ${ }^{8}$ extended such an analysis to Direct Injection (DI) CAI engines, highlighting the central influence of air-fuel stratification for a late injection timing. Similarly to Mori et $a l .{ }^{5}$, Adomeit et al. ${ }^{8}$ identified a larger mixture stratification for EGRB strategy than for NVO strategy. In addition to burnt gas stratification, DI implies a significant fuel stratification that can be used to act on combustion progress.

Knop et $\mathrm{al}^{7}$ went further along this path thanks to a numerical tool simultaneously describing mixture formation and heat release. Similarly to Koopmans et al. ${ }^{4}$ and Mori et $a l .^{5}$, the validation of the numerical approach relied on a direct comparison with optical diagnostics results, the key difference being that the numerical quantity to be compared with experimental observation of combustion is numerical heat release. As a consequence, once validated through comparison with experiment, the conditions for numerical early ignition spots can be related to local mixture properties. In coherence with Mori et al. ${ }^{5}$ and Adomeit et al. ${ }^{8}$, Knop et al. ${ }^{7}$ identified a distinct mixture structure for NVO and EGRB approaches. For the NVO approach, there was a strong correlation between local dilution rate and temperature, which also means a weak dilution variation for a given temperature. As a consequence, temperature is the predominant quantity and the temperature field defines the successive local ignitions. For the EGRB approach, dilution stratification was wider and less correlated with temperature. The influence of local dilution rate became predominant over temperature and defined the location of early ignition spots.
To the best of author's knowledge, no one ever expanded such 3D CFD analysis works to the behaviour on a complete CAI operating map, so that it is unknown whether such conclusions are general. The main objective of present study is to obtain a more general conclusion for the NVO strategy of CAI combustion mode.

\section{Combustion modelling in CAl engines}

Modelling combustion in CAI engines is a difficult task because of the intrincate effects of flow motion, mixture formation and fuel kinetics. A large number of previous approaches failed at correctly reproducing CAI combustion mode on a complete operating map due to a lack of accounting for at least one of these three key inputs. Non-dimensional ${ }^{6 ; 13-20}$ or quasi-dimensional multi-zone approaches ${ }^{21-23}$ cannot precisely describe flow motion and mixture formation. Heat release can be reproduced with multi-zone approaches by imposing the appropriate temperature stratification ${ }^{24}$ but this approach is neither predictive nor adapted to operating points for which dilution stratification controls heat release. 3D CFD approaches with excessive simplification of kinetics description or of fuel description (a single compound to emulate gasoline, for example) fail at accurately predicting combustion on multiple operating points because of a lack of precision on the kinetics side. In the present paper, the objective was to take all aspects into account, which required the combination of gasoline emulation and detailed kinetics solving at reasonable CPU cost as well as flow motion and mixture formation description with 3D CFD modelling. The chemistry-related aspects combine multiple steps that are detailed hereafter with the objective of simultaneously reaching precision and CPU-efficiency for kinetics description.

\section{Gasoline surrogate}

CAI combustion mode is a HCCI concept designed to be applied to gasoline-fuelled engines. The modelling of the combustion of a full blend gasoline is still nowadays too demanding for existing CPU resources. The most common strategy to circumvent this issue is to define a gasoline surrogate, which is a set of a few compounds that accurately mimicks the properties of real gasoline but alleviates the CPU burden.

An accurate emulation of gasoline with a mixture of only a few compounds requires the choice of the compounds and the identification of a restricted set of key properties to match. Pera and Knop ${ }^{9}$ notably proposed a methodology to 
maximise the number of reproduced properties by carefully selecting the set of constraints that define the proportions. This methodology only requires the identification of some basic properties of a given gasoline sample or set of samples (RON, MON, and the content in $C, H$, and $O$ atoms) to reproduce the key properties relevant to CAI operation (mainly auto-ignition delays and lower heating value). The experimental validation of a deduced ternary surrogate (a mixture of $13.7 \%$-heptane, $42.9 \%$ iso-octane, and $43.4 \%$ toluene in molar fractions) for a commercial gasoline on CAI operating points demonstrated the soundness of the approach ${ }^{10}$. We therefore selected the same approach for present computations.

\section{Detailed kinetics mechanisms}

Knop et al. ${ }^{10}$ identified 6 mechanisms for TRF mixtures ${ }^{15 ; 18 ; 25-28}$ and tested them against engine data under CAI combustion mode. They concluded that Andrae's mechanism ${ }^{18}$ was the best performer because of a distinct toluene reactivity. Although it was the best one, Andrae's mechanism ${ }^{18}$ did not perfectly capture sensitivity to engine operating conditions ${ }^{10}$, leaving open the question of a need for revision of toluene and/or iso-octane submechanism(s). In the meantime, Andrae revised its comprehensive submechanism for toluene ${ }^{11}$, which led to a slightly earlier combustion for all operating points but did not modify the conclusion about sensitivity to operating conditions.

Accordingly, we analysed the published measurements of auto-ignition delays at engine-relevant conditions for the other surrogate components, namely $n$-heptane and iso-octane, and compared the observed trends with the predictions of existing detailed kinetics mechanisms. While accuracy is satisfactory for $n$-heptane, we observed a mismatch in the prediction of auto-ignition delay trend for iso-octane: all mechanisms predict a Negative Temperature Coefficient (NTC) behaviour at all conditions but experiments show a different trend for the relatively high pressures relevant to lean or stoichiometric engine operation. To illustrate this statement, Fig. 1 depicts the evolution with temperature of auto-ignition delays for stoichiometric $n$-heptane/air and iso-octane/air mixtures at $40 \mathrm{bar}$. $n$ Heptane/air mixture has an obvious NTC area. On the other hand, although the iso-octane/air mixture presents a slower auto-ignition delay evolution in the intermediate temperature domain than in the high temperature domain, the intermediate temperature domain is still a Positive Temperature Coefficient (PTC) area. To confirm the visual impression, trendlines were computed according to the approach of Vandersickel et al. ${ }^{29}$ and superimposed to measurements in Fig. 1.

An erroneous prediction of iso-octane reactivity in the intermediate temperature domain could be the origin of the difficulty to reproduce the sensitivity to operating conditions. Due to the inherent in-cylinder temperature stratification ${ }^{30}$, an incorrect sensitivity of auto-ignition delay to temperature would locally time-shift the heat release and globally spatially-shift the most reactive area. For this reason, the present work included an attempt to improve the $i$ so-octane subset, especially in the intermediate temperature domain, in order to finally improve the ignition delay prediction for TRF mixtures at engine-relevant conditions. In the following, the results of engine modelling with Andrae's mechanism ${ }^{18}$ is compared to this altered mechanism to outline the sensitivity of CAI combustion mode to intermediate temperature kinetics.

\section{Efficient integration of kinetics in $3 D C F D$ computations}

Once an accurate kinetic mechanism has been identified, there is still the question of accurately and efficiently combining chemistry and flow motion within the 3D CFD code. Direct chemistry solving in each cell provides the required precision but is extremely demanding on CPU resources. Mechanism reduction restricts the demand on CPU resources but jeopardises precision. Grouping of cells with similar conditions to reduce the number of conditions for which kinetics must be solved is CPU-efficient but a given grouping strategy does not produce the same precision level for all condtions limiting the generality of conclusions. An alternative solution is kinetics pre-processing through the creation of look-up tables ${ }^{31-37}$. Accordingly, kinetic mechanism is solved in idealised conditions and relevant results are stored in look-up tables that are then read during the 3D CFD computation. There is no loss in precision from kinetics or through cell grouping but there is a significant additional pre-processing work. However, such a pre-processing has only to be done once and for all for each fuel, which makes the method especially efficient when multiple points are modelled on an engine operating map.

In the present study, we selected the latest version of the Tabulated Kinetics of Ignition (TKI) model ${ }^{37}$ for such a purpose. Consequently, for each mechanism considered for the 3D CFD part of the study, a specific look-up table is created according to the method described in ${ }^{37}$ considering the gasoline surrogate composition (13.7 $\mathrm{mol} \%$

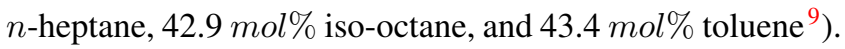



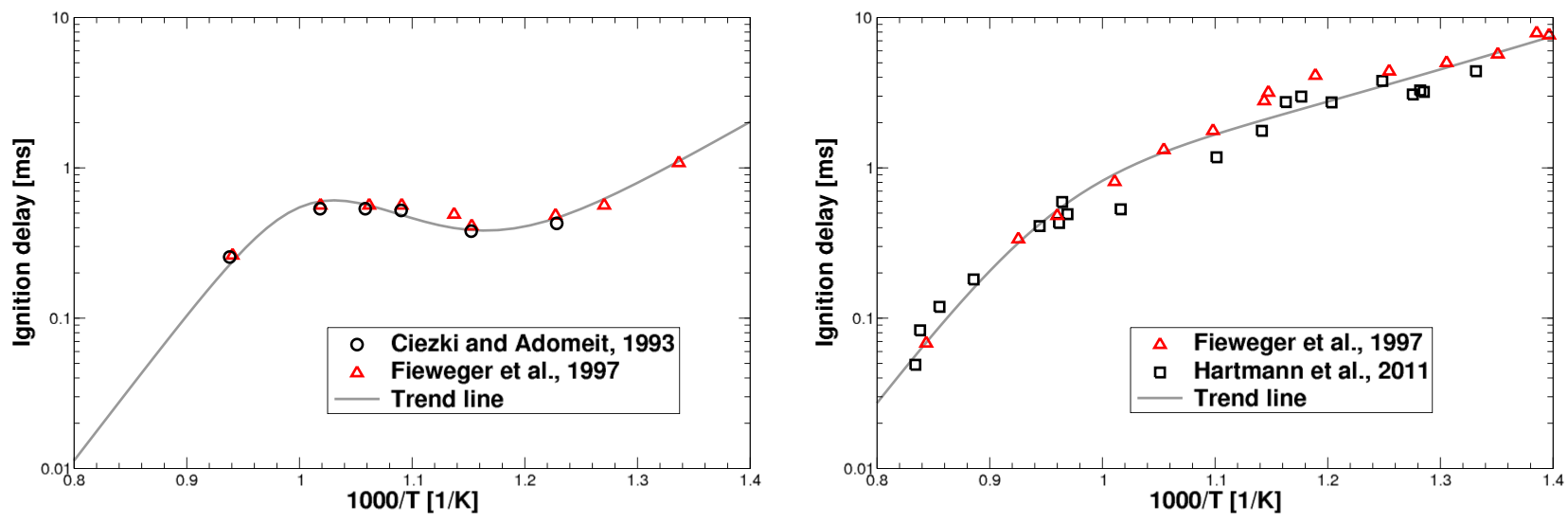

Figure 1. Comparison of auto-ignition delays of stoichiometric $n$-heptane/air (left) and $i s o$-octane/air (right) mixtures at $40 \mathrm{bar}$. Symbols are experimental measurements. Lines are trendlines computed according to the approach of Vandesickel et al. ${ }^{29}$

The TKI model ${ }^{37}$ provides fuel auto-ignition delays and a description of the consequent heat release, deduced from detailed chemistry calculations performed prior to the CFD simulation. The TKI look-up tables are a collection of closed-volume, constant-enthalpy auto-igniting reactors stored for all conditions embraced in engines (all possible combinations of pressure, temperature, mixture strength and dilution rate). The stored quantities are then read during the 3D CFD simulation depending on the local in-cell conditions with additional interpolation if needed. The table input parameters are the fresh gas temperature, pressure, fuel/air equivalence ratio and dilution rate.

\section{Alternative mechanism for $i s o-o c t a n e$}

Before altering any mechanism, we compared the predictions of 5 existing mechanisms for TRF mixtures ${ }^{11 ; 15 ; 25 ; 26 ; 28}$ to experimental auto-ignition delay measurements in shock tubes $^{38-41}$ for lean and stoichiometric conditions (Fig. 2), modelling shock tube ignition assuming a homogeneous adiabatic environment with a constant volume, constant internal energy constraint. Measurements in shock tubes were exclusively selected because experimental conditions in such devices are very similar to end-of-compression conditions in CAI engines, combining high pressure (20 to $40 \mathrm{bar}$ ) and high temperature (900 to $1300 \mathrm{~K}$ ) for stoichiometric or slightly lean conditions ${ }^{10 ; 42}$. Confirming trend from Fig. 1, the gathering of experimental data emphasized the lack of NTC behaviour for iso-octane at all engine-relevant pressures for lean to stoichiometric conditions (see display of all experimental data in Supplementary Material).

All identified mechanisms able to describe TRF reactivity predicted a marked NTC behaviour whatever the fuel/air equivalence ratio or the pressure, as examplified in Fig. 2 at $p=40 b a r$ (a complete comparison of measurements with predictions for all pressures is available in Supplementary Material). However, broadly speaking, not all litterature mechanisms predict a NTC behaviour as at least the mechanisms of Curran et al. ${ }^{43 ; 44}$ are in better agreement with experimental trend for iso-octane auto-ignition delay evolution in the intermediate temperature domain in shock tubes but unable to describe TRF mixtures.

Similarly to in-engine conditions ${ }^{10}$, Andrae's mechanism ${ }^{11}$ is the best overall mechanism with only a moderate NTC behaviour. As a consequence, Andrae's mechanism was selected as our reference mechanism. The main discrepancy between experiment and Andrae's mechanism lies between 800 and $1000 K$. Furthermore, the prediction of a NTC behaviour rather than a PTC behaviour may lead to an erroneous identification of the most reactive regions in an actual engine combustion chamber because of the underlying stratification of mixture temperature.

Accordingly, an alteration of the iso-octane subset of Andrae's mechanism ${ }^{11}$ was considered to obtain a PTC behaviour in the intermediate temperature domain. There is no claim to thoroughly define rigorous reaction rates but rather a will to mathematically reproduce experimental trends in order to outline the influence of intermediate temperature kinetics on such a combustion mode.

Andrae's mechanisms ${ }^{11 ; 18}$ include a comprehensive submechanism for toluene and reduced subsets for isooctane and $n$-heptane. Only the $i s o$-octane subset was altered maintaining a description with global reaction pathways relevant to auto-ignition under engine-relevant conditions (reduced mechanism). For guidance in the choice of reactions and corresponding rates, we identified the main reaction pathways in the detailed mechanisms of Curran 

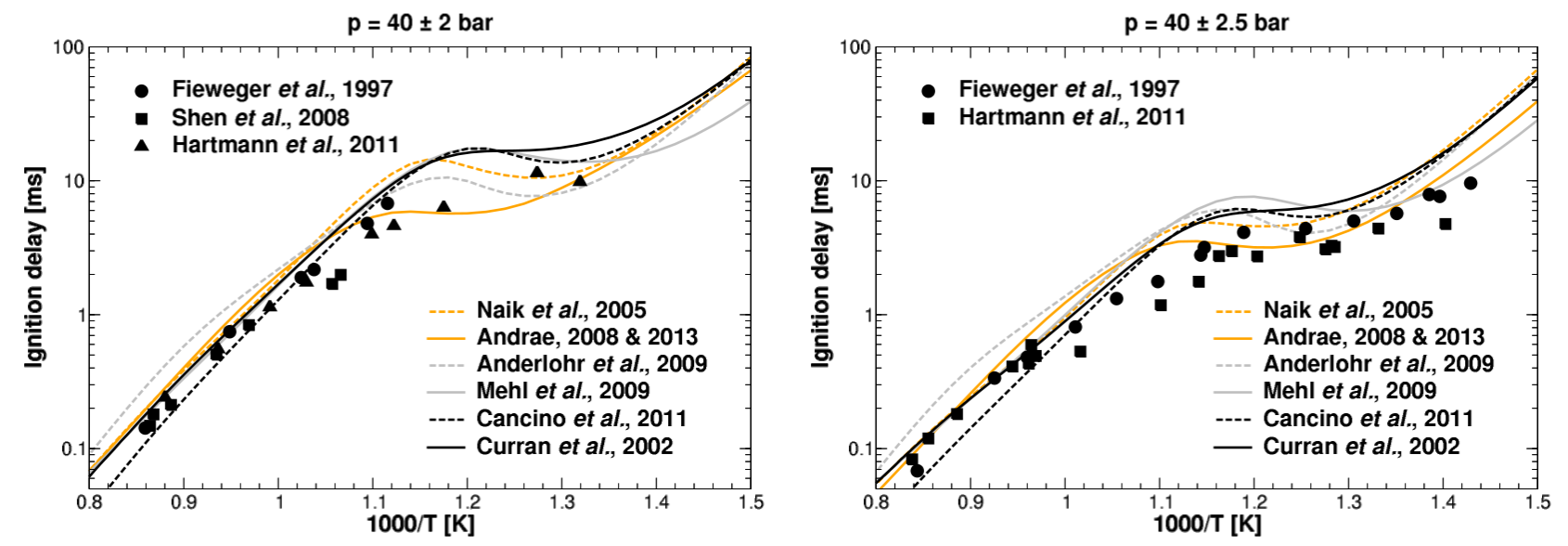

Figure 2. Comparison of auto-ignition delay measurements (symbols) with predictions (lines) for existing mechanisms at $p=40$ bar. Left: lean $i s o-o c t a n e / a i r$ mixture $(\phi=0.5)$. Right: stoichiometric $i$ so-octane/air mixture

et $a .^{43 ; 44}$ and lumped isomers to limit the number of included species. The resulting subset for iso-octane is detailed in Table 1. Most reaction rates came either from reference Andrae's mechanisms ${ }^{11 ; 18}$ or from lumping of reactions from the detailed mechanisms of Curran et al. ${ }^{43 ; 44}$. Reactions (R4), (R6), (R7) and (R8) are controlling reactivity in the intermediate temperature domain and were tuned according to the objective to match at best experimental measurements in shock tubes. Optimisation started with values coming from lumping of reactions from the detailed mechanisms of Curran et al. ${ }^{43 ; 44}$ and progressed to avoid the slightly late auto-ignition timing obtained with the detailed mechanisms of Curran et al. ${ }^{43 ; 44}$ while conserving the PTC behaviour.

Figure 3 depicts the change in ignition delay prediction at $p=40 b a r$ compared to Andrae's mechanism ${ }^{11}$. As intended, the trend in delay evolution in the intermediate temperature domain (800 to $1000 \mathrm{~K}$ ) differs, which induces a significant difference in delay quantification around $900 \mathrm{~K}$ at 40bar: auto-ignition delay is up to $1 \mathrm{~ms}$ or $25 \%$ shorter (and in significantly better agreement with experiment), which is a huge difference in terms of auto-ignition timing at engine conditions. Additionally, the new subset better quantifies the influence of fuel/air ratio and the auto-ignition delays between 900 and $1200 K$ (always shorter than for Andrae's mechanism ${ }^{11}$ ). A more complete comparison with experimental auto-ignition delay measurements is available in Supplementary Material).

Observed changes in auto-ignition delay prediction may seem minor when looking at logarithmic diagrams (Fig. 3) but differences of $1 \mathrm{~ms}$ at relevant engine speeds correspond to 5 to $20 \mathrm{cad}$, which is significant when looking for accurate combustion timing prediction.

\section{Computational approach}

Attaining CAI combustion mode relies on the trapping of a large amount of burnt gases from the preceding engine cycle. This strategy introduces a strong cycle-to-cycle coupling between multiple cycles as the end-of-expansion thermal state from a cycle influences the combustion timing and therefore the end-of-expansion thermal state of next cycle. The modelling of such a combustion mode consequently requires a multi-cycle approach. However, a 3D CFD multicycle computation on a large number of operating points is extremely demanding on CPU resources and certainly sub-optimal. To reduce the computational cost, we selected a two-step multi-cycle computational approach. The first step was multi-cycle system simulation in order to identify the fraction of trapped burnt gases and their temperature, both quantities being unaccessible on experimental side. The second step was 3D CFD multi-cycle computation initialised with experimental and system simulation data. The inclusion of pre-converged data from system simulation not only led to a large reduction in the number of required cycles for convergence of $3 \mathrm{D}$ CFD ( $2^{\text {nd }}$ and $3^{\text {rd }}$ cycles generally produced very similar results) but also removed any risk for misfire due to an improper initialisation. In the following, detailed 3D CFD results correspond to the converged cycles.

\section{System simulation}

We selected as system simulation approach the IFPENGINE library from the LMS Imagine.Lab AMESim platform ${ }^{47}$, a non-dimensional modelling approach, for its ability to quickly analyse a large quantity of operating points. The variety of available sub-models, which are representative of the most relevant engine components, 


\begin{tabular}{|c|c|c|c|c|c|}
\hline & Reaction & $A$ & $n$ & $E_{a}$ & References \\
\hline (R1) & $\mathrm{C}_{8} \mathrm{H}_{18}+\mathrm{HO}_{2}=\mathrm{C}_{8} \mathrm{H}_{17}+\mathrm{H}_{2} \mathrm{O}_{2}$ & $1.050 \mathrm{E}+02$ & 3.600 & 13775.0 & + \\
\hline (R2) & $\mathrm{C}_{8} \mathrm{H}_{18}+\mathrm{OH}=\mathrm{C}_{8} \mathrm{H}_{17}+\mathrm{H}_{2} \mathrm{O}$ & $5.250 \mathrm{E}+07$ & 1.800 & 1500.0 & $\dagger$ \\
\hline (R3) & $C_{8} H_{18}+H=C_{8} H_{17}+H_{2}$ & $1.120 \mathrm{E}+06$ & 2.750 & 6000.0 & $\dagger$ \\
\hline (R4) & $\mathrm{C}_{8} \mathrm{H}_{18}+\mathrm{O}_{2}=\mathrm{C}_{8} \mathrm{H}_{17}+\mathrm{HO}_{2}$ & $1.260 \mathrm{E}+14$ & 0.000 & 40150.0 & see text \\
\hline (R5) & $\mathrm{C}_{8} \mathrm{H}_{18}+\mathrm{O}=\mathrm{C}_{8} \mathrm{H}_{17}+\mathrm{OH}$ & $1.925 \mathrm{E}+05$ & 2.750 & 1750.0 & $\dagger$ \\
\hline (R6) & $\mathrm{C}_{8} \mathrm{H}_{18}=\mathrm{C}_{8} \mathrm{H}_{17}+\mathrm{H}$ & $2.125 E+18$ & -0.450 & 91250.0 & see text \\
\hline (R7) & $\mathrm{O}_{2} \mathrm{C}_{8} \mathrm{H}_{16} \mathrm{OOH}=\mathrm{C}_{8} \mathrm{H}_{16} \mathrm{OOH}+\mathrm{O}_{2}$ & $6.500 \mathrm{E}+21$ & -2.000 & 35000.0 & see text \\
\hline (R8) & $\mathrm{O}_{2} \mathrm{C}_{8} \mathrm{H}_{16} \mathrm{OOH}=\mathrm{OC}_{8} \mathrm{H}_{15} \mathrm{OOH}+\mathrm{OH}$ & $2.500 \mathrm{E}+11$ & 0.000 & 15000.0 & see text \\
\hline (R9) & $\mathrm{C}_{8} \mathrm{H}_{17} \mathrm{O}_{2}=\mathrm{C}_{8} \mathrm{H}_{16} \mathrm{OOH}$ & $1.135 \mathrm{E}+11$ & 0.000 & 22400.0 & $45, \dagger$ \\
\hline (R10) & $\mathrm{C}_{8} \mathrm{H}_{17} \mathrm{O}_{2}=\mathrm{C}_{8} \mathrm{H}_{16}+\mathrm{HO}_{2}$ & $8.530 E+35$ & -7.220 & 41490.0 & $\dagger$ \\
\hline (R11) & $\mathrm{C}_{8} \mathrm{H}_{16} \mathrm{OOH}=\mathrm{C}_{8} \mathrm{H}_{16}+\mathrm{HO}_{2}$ & $3.250 \mathrm{E}+21$ & -2.650 & 17350.0 & $\dagger$ \\
\hline (R12) & $\mathrm{C}_{8} \mathrm{H}_{17}+\mathrm{O}_{2}=\mathrm{C}_{8} \mathrm{H}_{17} \mathrm{O}_{2}$ & $5.000 \mathrm{E}+12$ & 0.000 & 0.0 & $\dagger$ \\
\hline (R13) & $\mathrm{C}_{8} \mathrm{H}_{17}+\mathrm{O}_{2}=\mathrm{C}_{8} \mathrm{H}_{16}+\mathrm{HO}_{2}$ & $1.000 \mathrm{E}-18$ & 0.000 & 5000.0 & $\dagger$ \\
\hline (R14) & $C_{8} H_{17}=C_{8} H_{16}+H$ & $1.300 \mathrm{E}+12$ & 0.600 & 37000.0 & $\dagger$ \\
\hline (R15) & $\mathrm{C}_{8} \mathrm{H}_{17} \rightarrow i \mathrm{C}_{4} \mathrm{H}_{8}+\mathrm{CH}_{2} \mathrm{CHCH}_{3}+\mathrm{CH}_{3}$ & $1.280 \mathrm{E}+12$ & 0.000 & 49000.0 & 46 \\
\hline (R16) & $\mathrm{OC}_{8} \mathrm{H}_{15} \mathrm{OOH} \rightarrow \mathrm{OC}_{8} \mathrm{H}_{15} \mathrm{O}+\mathrm{OH}$ & $3.981 \mathrm{E}+15$ & 0.000 & 43000.0 & 45 \\
\hline (R17) & $\mathrm{C}_{8} \mathrm{H}_{16} \rightarrow i \mathrm{C}_{4} \mathrm{H}_{8}+i \mathrm{C}_{4} \mathrm{H}_{8}$ & $2.000 \mathrm{E}+12$ & 0.000 & 45000.0 & $\dagger$ \\
\hline (R18) & $\begin{array}{l}\mathrm{OC}_{8} \mathrm{H}_{15} \mathrm{O}+\mathrm{O}_{2} \rightarrow \mathrm{H}_{2} \mathrm{CCCH}_{2} \\
+\mathrm{C}_{2} \mathrm{H}_{3}+2 \mathrm{CH}_{2} \mathrm{O}+\mathrm{CH}_{3}+\mathrm{HO}_{2}\end{array}$ & $2.450 \mathrm{E}+13$ & 0.000 & 32000.0 & 46 \\
\hline (R19) & $i \mathrm{C}_{4} \mathrm{H}_{8}+\mathrm{O}_{2} \rightarrow \mathrm{C}_{2} \mathrm{H}_{4}+\mathrm{C}_{2} \mathrm{H}_{3}+\mathrm{HO}_{2}$ & $2.000 \mathrm{E}+14$ & 0.000 & 35900.0 & 46 \\
\hline \multirow[t]{2}{*}{ (R20) } & $i \mathrm{C}_{4} \mathrm{H}_{8}=\mathrm{CH}_{2} \mathrm{CHC} \cdot \mathrm{H}_{2}+\mathrm{CH}_{3}$ & $1.920 \mathrm{E}+66$ & -14.220 & 128100.0 & 44 \\
\hline & Reverse Arrhenius coefficients & $2.089 \mathrm{E}+59$ & -13.230 & 29530.0 & \\
\hline
\end{tabular}

Table 1. Revised iso-octane submechanism ( ${ }^{\dagger}$ indicates reaction defined through lumping of isomers from Curran et al. ${ }^{44}$ )
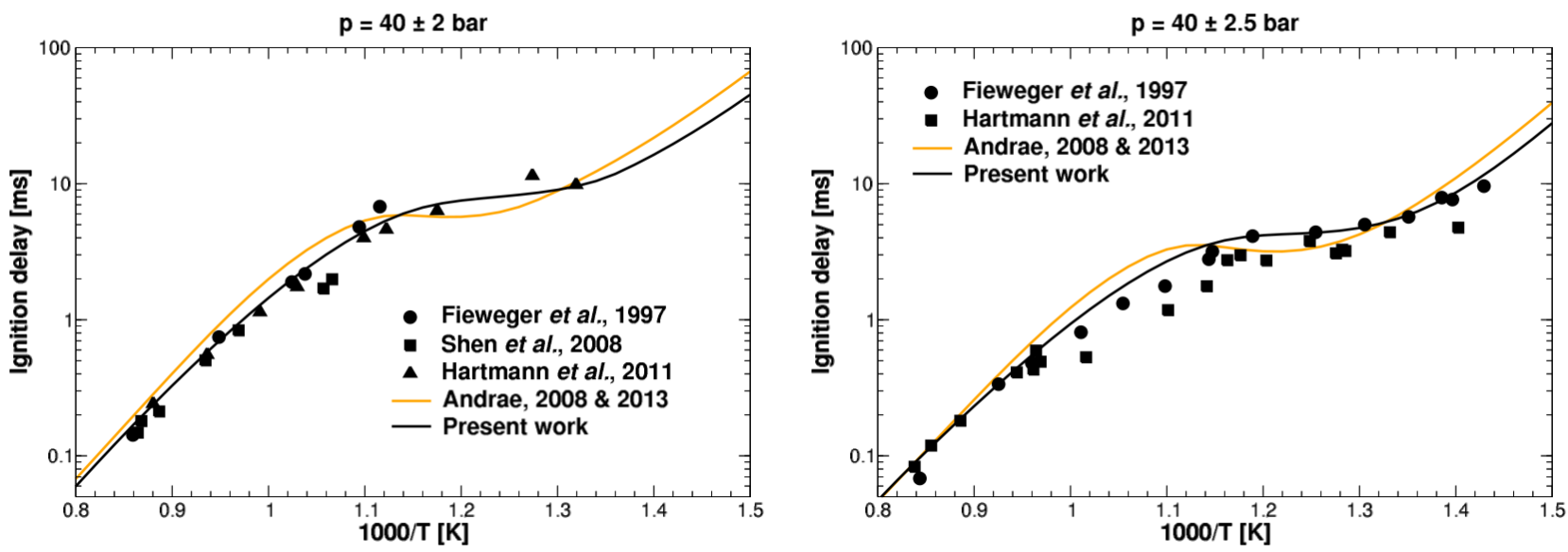

Figure 3. Comparison of auto-ignition delay measurements (symbols) with predictions (lines) for original and revised mechanisms at $p=40 \mathrm{bar}$. Left: lean $i s o$-octane/air mixture $(\phi=0.5)$. Right: stoichiometric $i$ so-octane/air mixture

allowed for an uncomplicated, accurate description of the CAI engine ${ }^{10 ; 42 ; 48}$.

We checked the tool's validity by comparing experimental and numerical quantities, such as instantaneous pressure traces in the intake port, in the exhaust port, and in the combustion chamber, as well as cycle-averaged flow rates, intake and exhaust gas temperatures, and FAERs. We were able to build confidence for the extracted additional non-measurable data (mainly in-cylinder temperature and mixture composition) by carefully checking that the physical phenomena we observed on the dynometer were accurately reproduced.

To maintain consistency throughout the study, we extracted the thermodynamic gas properties from the detailed chemistry scheme selected for 3D CFD computations. A
Woschni model was used to describe the heat exchanges with walls ${ }^{49}$. Due to the short and sudden heat release under CAI operating conditions, a single Wiebe expression provided a sufficiently high level of accuracy for the combustion description ${ }^{50}$. Start and duration of combustion were tuned to reproduce the experimental rate of heat release.

We further checked the convergence on combustion description and on gas temperature in the intake and exhaust circuits towards the resulting experimental values. Once convergence was reached, the engine's steady state behaviour was accurately reproduced for each operating point. The mixture's composition and temperature at the end of expansion stroke were extracted to initialise the first cycle of 3D CFD computations. 


\section{$3 D C F D$}

We performed the 3D CFD computations with an in-house code called IFP-C3D ${ }^{51}$. This code is a RANS parallel (MPI) solver for reactive compressible gas flows with sprays dedicated to multi-physics three-dimensional simulations of internal combustion engines. Turbulence modelling relied on the k- $\epsilon$ RNG model ${ }^{52}$ while we modelled the law-ofthe-wall with the model of Kays and Crawford ${ }^{53}$. Present computations included tetrahedra-dominant meshes with a typical cell size of $0.5 \mathrm{~mm}$ and described the complete 4stroke engine cycle. We used intake and exhaust pressure measurements to define 3D CFD boundary conditions, while in-cylinder pressure was the main quantity for CFD result validation. As detailed previously, the auto-ignition prediction and the description of the subsequent kineticallydriven heat release relied on the Tabulated Kinetics of Ignition (TKI) model ${ }^{37}$ and a ternary gasoline surrogate ${ }^{9}$.

\section{Engine setup and selected conditions}

To isolate the influence of the location within the operating map from the effect of standard control inputs (valve timing, injection timing, fuel/air ratio,...), we selected operating points obtained for a unique engine set-up and identical settings for main controlling parameters. Accordingly, there was no change in compression ratio (geometric and effective) or fuelling method (only port fuel injection with given injection timing) between operating points. We chose a single valve strategy (same valve lift profiles, same valve opening timings) and operation remained stoichiometric. However, to supplement the analysis with the influence of fuel/air ratio, mixture leaning was additionally considered on a single operating point.

The present study was performed on a port fuel injection single-cylinder research engine with a displacement of $0.5 l$ and a compression ratio of 12.0:1 (see details in Table 2). Previous studies have already described this engine and its variable valve actuation device in detail ${ }^{12 ; 42 ; 48}$.

\begin{tabular}{lr}
\hline Bore [mm] & 82.7 \\
\hline Stroke [mm] & 93.0 \\
\hline Conrod length [mm] & 143.0 \\
\hline Compression ratio [-] & $12.0: 1$ \\
\hline
\end{tabular}

Table 2. Main engine specifications

Control over the amount of burnt gases is a key for successful implementation of CAI combustion in an engine. Two valve lift strategies are possible: negative valve overlap $^{4 ; 7 ; 42 ; 54 ; 55}$ and exhaust gas rebreathing ${ }^{12 ; 48 ; 56}$. In the present study, we considered the negative valve overlap strategy (Fig. 4), which relies on an early exhaust valve closure and a low peak valve lift to restrict the exhaust blowdown efficiency and, therefore, to directly trap the desired amount of burnt gases.

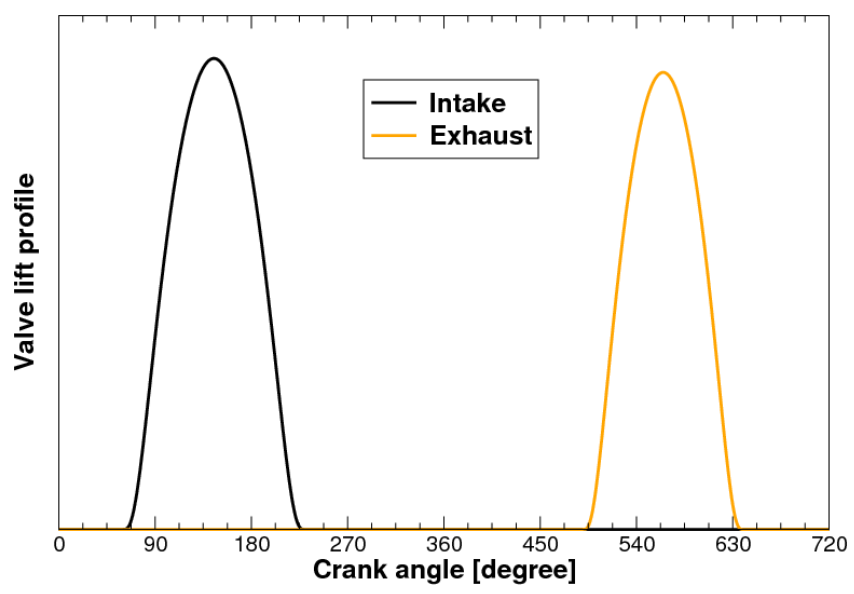

Figure 4. Intake and exhaust valve lift profiles at reference timings (360 $\mathrm{cad}$ is combustion TDC)

All selected operating points were part of the measurements from ${ }^{10}$ and only results with gasoline surrogate fuelling were considered in the present study to avoid any possible doubts about discrepancy between experiment and modelling related to fuel selection. We purposely selected operating points on the border of the operating map because, as detailed in ${ }^{10}$, they ensure the consideration of all phenomena that can be encountered within the core of the operating map. We chose the reference valve timing from ${ }^{10}$ as unique valve timing during the present study. The consequent valve lift profiles are depicted in Fig. 4.

Table 3 summarises the modelled operating points, that define the lower and higher limits of the operating map at low, intermediate and high engine speed. Higher speed operation was impossible as the lower and higher load limits merged at 3500 RPM. Lower speed operation was also difficult as the lower load limit quickly raised when reducing engine speed, leading to a merging of high and low limits at around 1000 RPM. For all those operating points, an analysis of mean in-cylinder quantities was already presented in ${ }^{10}$. The purpose of present work is to identify whether or not significant differences in local conditions occured when changing speed and/or load and to emphasize the influence of changing thermodynamic conditions on mixture reactivity.

\section{Results}

The analysis of 3D CFD results aimed at identifying the influence of local conditions and of kinetics on the onset and on the progress of combusion over the complete operating map. However, before the analysis of 3D fields, we first had to assess the representativity of such numerical results. 


\begin{tabular}{cccc}
\hline Acronym & $\begin{array}{c}\text { Engine speed } \\
\text { [RPM] }\end{array}$ & $\begin{array}{c}\text { Engine load - } \\
\text { IMEP [bar] }\end{array}$ & $\begin{array}{c}\text { FAER } \\
{[-]}\end{array}$ \\
\hline \hline 1HSR & 1500 & 3.7 & Stoichiometric \\
\hline 1LSR & 1500 & 2.8 & Stoichiometric \\
\hline 2 HSR & 2500 & 2.4 & Stoichiometric \\
\hline 2LSR & 2500 & 1.6 & Stoichiometric \\
\hline 2LLR & 2500 & 1.6 & Lean $(\phi=0.9)$ \\
\hline 3BSR & 3500 & 1.5 & Stoichiometric
\end{tabular}

Table 3. Operating point characteristics. Acronyms are formed as follows: number indicates engine speed, first letter differentiates high load $(H)$ from low load $(L)$ operating points $(B$ indicates that both limits are simultaneously reached), second letter indicates if the mixture was stoichiometric (S) or lean (L), and last letter indicates that the reference $(R)$ valve timing was used.

For this purpose, we first compared the numerical and experimental in-cylinder pressure traces for all considered operating points for two different descriptions of chemical kinetics: either Andrae's mechanism ${ }^{11}$, or the proposed revised mechanism with an updated description of $i s o$-octane reactivity.

\section{Validation of the modelling approach}

To validate the modelling approach, we compared the experimental and numerical pressure traces for all 6 operating points (Fig.5). Numerical results obtained with Andrae's mechanism ${ }^{11}$ outlined a lack of reactivity, which is coherent with the overestimation of auto-ignition delays observed above $900 K$ (Fig. 3). As the combustion mode fully relies on temperature increase through burnt gas trapping and compression to promote the onset of combustion, an overestimation of auto-ignition delays implies a delay in early heat release. As combustion progress is dictated by a progressive auto-ignition of the fresh charge triggered by the heat release of already burning areas, any delay in early heat release further delays later heat release or even leads to partial fuel conversion when delay is excessive and combustion starts in the expansion stroke. The overdelayed combustion timing obtained for all operating points with Andrae's mechanism ${ }^{11}$ prevented from drawing any strong conclusion about the sensitivity to the location on the operating map.

With the revised mechanism, the timing and intensity of heat release were significantly better reproduced. Fuel conversion was complete for all cases and combustion timing was well-reproduced for most cases. Only the high load operating point at $2500 R P M$ suffered from a significant delay in combustion timing. As a consequence, the revised mechanism not only accurately predicted the onset and progress of combustion but was also correctly sensitive to the change in mixture conditions when shifting from one operating point to another. The analysis of 3D fields derived from the computations with the revised mechanism was therefore a stronger basis to identify the influence of local conditions on the development of combustion over the complete operating map of a CAI engine. The improved prediction of combustion timing and heat release with the revised mechanism also stresses the importance of the intermediate temperature kinetics for such a combustion mode and the still topical need for a better description of alkane kinetics in such conditions.

\section{Mixture state at combustion onset}

To analyse the influence of local mixture state on combustion onset, we extracted 3D CFD fields when mixture is already reactive but before any major heat release occurred. As the engine is port fuelled with an injection timing during exhaust stroke, air and fuel were almost perfectly mixed, so that local mixture can be univocally described based only on temperature and dilution rate. Accordingly, Figs. 6 and 7 depicts temperature and dilution rate fields $20 \mathrm{cad}$ bTDC. The visualisation plane is located $5 \mathrm{~mm}$ above head gasket plane because it is the most reactive area. In each subfigure, a cross locates the early reaction spots to help identify the most favourable conditions.

The field visualisation (Figs. 6 and 7) of all operating points underlines a similar global behaviour whatever the engine speed or the engine load. Whatever the operating conditions, air and burnt gas mixing is quite effective, removing any local pockets of totally unmixed fresh or burnt gases. Mixture homogeneity only degrades when engine speed increases because there is less time to mix air and burnt gases. However, mixing is still effective enough at $3500 \mathrm{rpm}$ to limit the standard deviation of dilution rate below $4 \%$ of the average value. This is notably different from the exhaust gas rebreathing strategy ${ }^{5 ; 7}$ that promotes local heterogeneity. As outlined by ${ }^{57}$, for the NVO strategy, air and burnt gas mixing is promoted by the low peak valve lifts inducing large velocities for incoming air and an intense turbulent mixing with trapped gases.

As mixture was not largely heterogeneous, the large difference in temperature between fresh and burnt gases did not induce a significant temperature stratification. However, given the higher mixture temperature than for standard SI operation and the larger turbulence intensity, heat losses to the walls were significantly larger for CAI operation ${ }^{58}$, which, in turn, implied a larger in-cylinder temperature stratification near walls. A noticeable spatial temperature stratification is consequently visible $20 \mathrm{cad}$ bTDC with highest temperatures in the central area. 


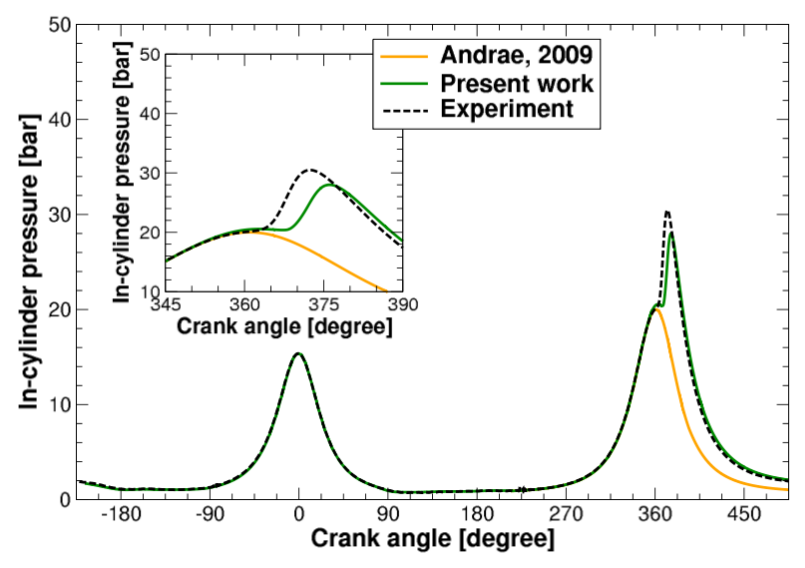

(a) $1 \mathrm{LSR}$

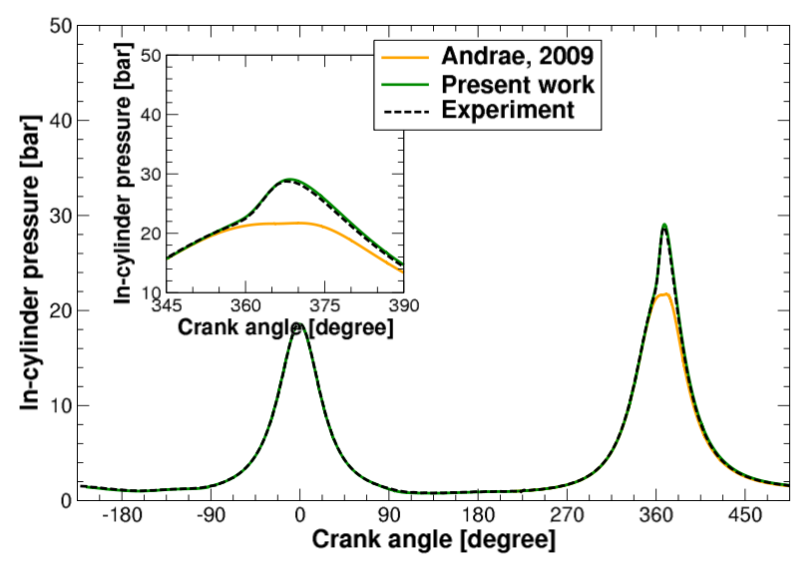

(c) $2 \mathrm{LSR}$

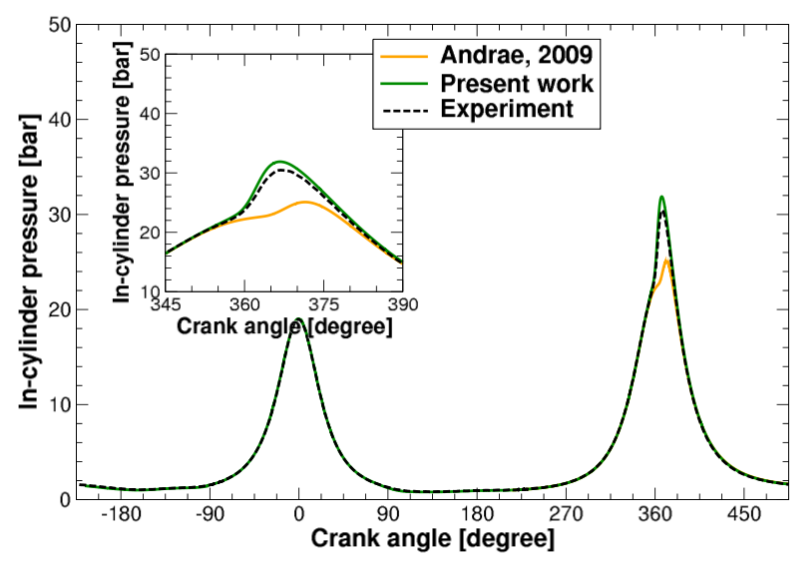

(e) 2LLR

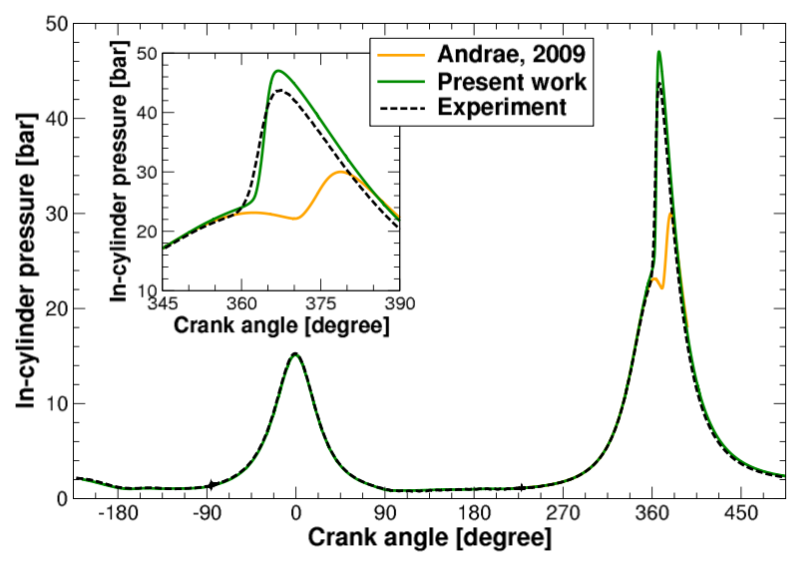

(b) $1 \mathrm{HSR}$

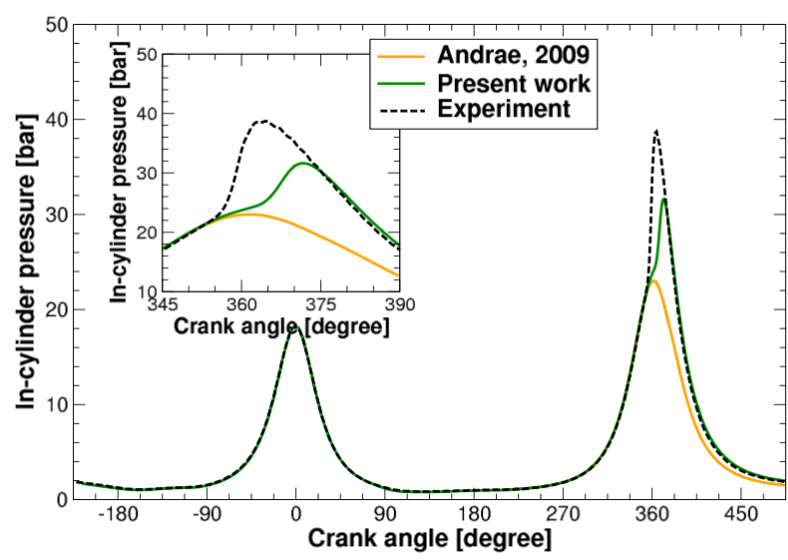

(d) $2 \mathrm{HSR}$

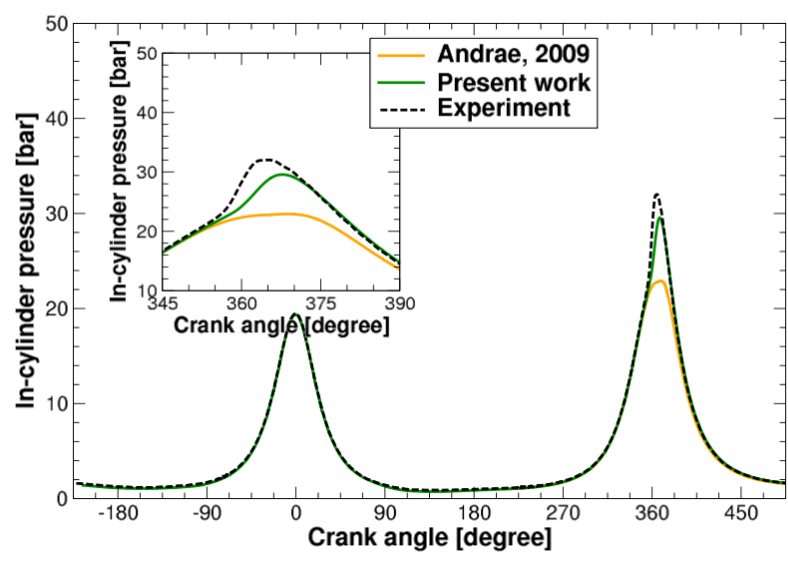

(f) 3BSR

Figure 5. Comparison of experimental and numerical pressure traces

As a consequence, temperature stratification in CAI engines is directly related to burnt gas trapping through both effects (mixing cold and hot gases as well as enhanced near-wall temperature stratification because of a globally hotter mixture) but not directly in a proportional way, as following statistical analysis of in-cylinder conditions will further demonstrate.

\section{Statistical analysis of local conditions in the combustion chamber}

CAI combustion mode is kinetically-controlled and the most influent quantities with respect to kinetics are temperature, fuel/air ratio and dilution rate. In the present study, we exclusively selected PFI operation with closed-valve 


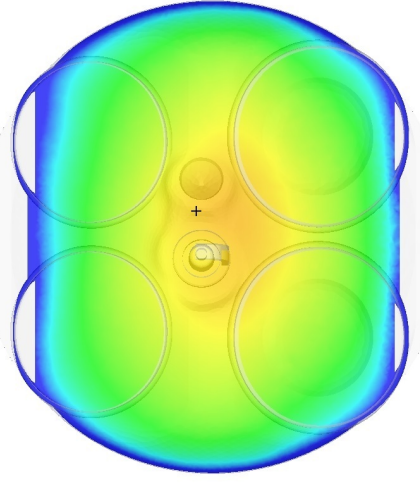

(a) $1 \mathrm{LSR}$

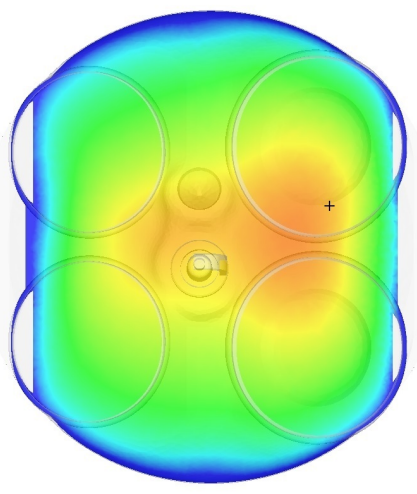

(c) $2 \mathrm{LSR}$

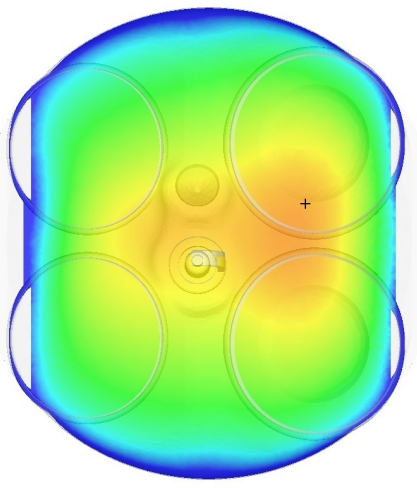

(e) 2 LLR

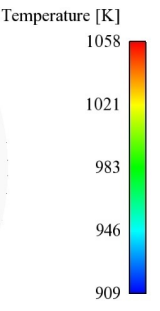

Temperature $[\mathrm{K}]$

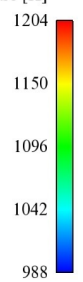

Temperature $[\mathrm{K}]$

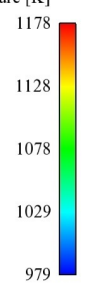

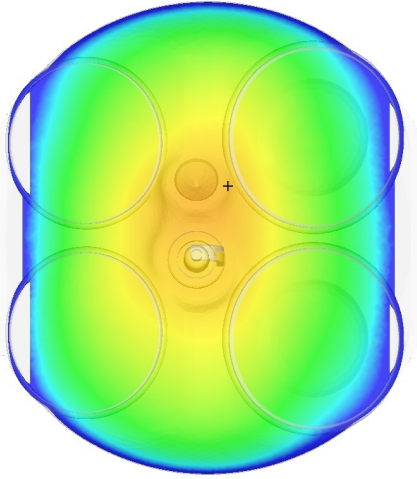

Temperature $[\mathrm{K}]$

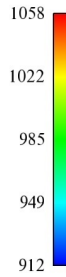

(b) $1 \mathrm{HSR}$

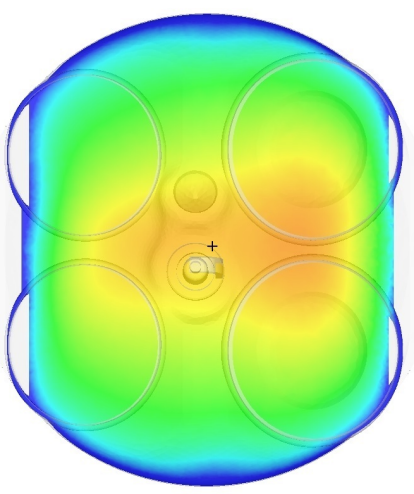

emperature $[\mathrm{K}]$

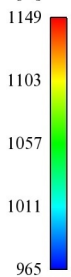

(d) 2HSR

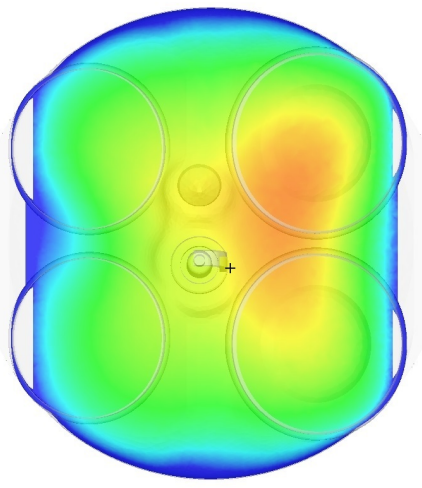

Temperature $[\mathrm{K}]$

1183
1128
1073
1018

Figure 6. Temperature field $20 \mathrm{cad}$ bTDC ('+' signs indicate the location of the first ignition spots)

injection timing to ensure the best possible air/fuel mixture homogeneity, eliminating the influence of local fuel/air equivalence ratio on kinetics. As a consequence, local temperature and local dilution rate were the main driving forces.

Obtaining CAI combustion mode through NVO strategy implies a strong correlation between local dilution (the source for high temperature gases) and local temperature. On the other hand, because of additional effects such as heat losses to the walls, temperature and dilution are not just proportional. Furthermore, temperature and dilution rate have opposed effects on kinetics: increasing the dilution rate delays auto-ignition, while increasing temperature advances auto-ignition. To analyse these intricate effects, we built up correlation diagrams between temperature and dilution (Fig. 8) on which we located the first auto-ignition spots.

Figure 8 displays statistics of in-cylinder mixture state 20 cad bTDC, with scales centered on mean in-cylinder value $(\mu)$ and spreading on each side along 2 standard deviations $(\sigma)$, i.e. with a scale from $\mu-2 \sigma$ to $\mu+2 \sigma$. Each diagram in Fig. 8 contains 3 subplots: a central joint probability diagram for temperature and dilution rate, as well as 2 lateral diagrams providing individual distributions for each quantity 


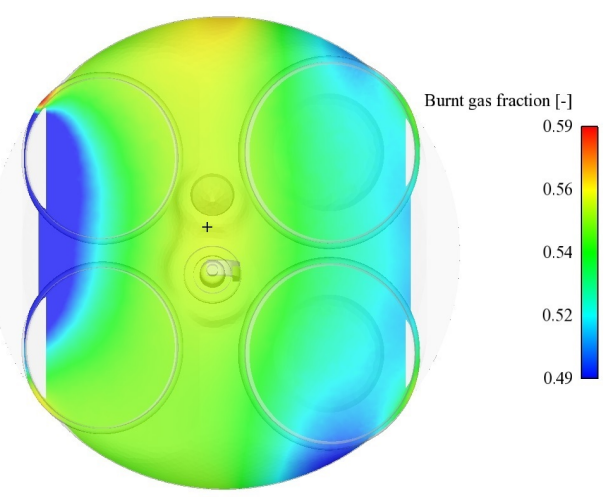

(a) $1 \mathrm{LSR}$

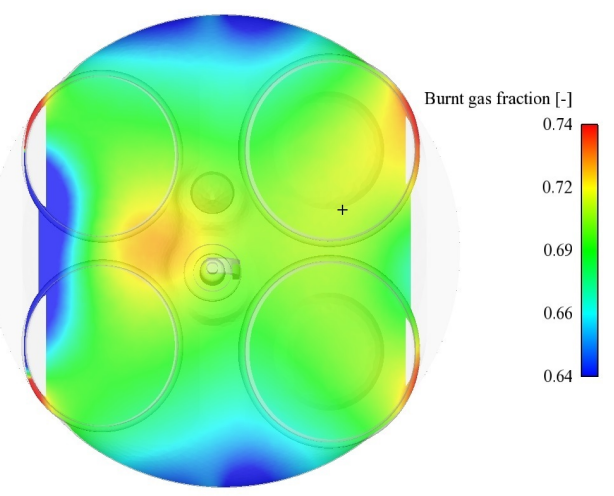

(c) $2 \mathrm{LSR}$

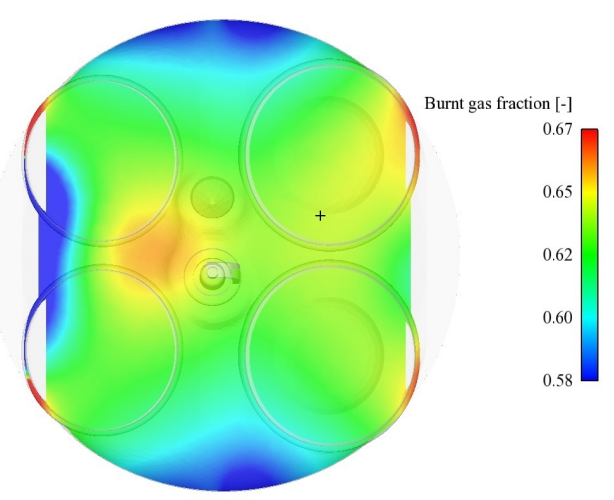

(e) $2 \mathrm{LLR}$

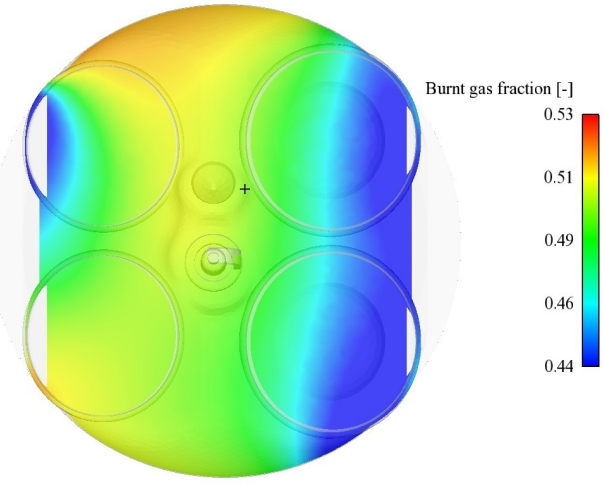

(b) $1 \mathrm{HSR}$

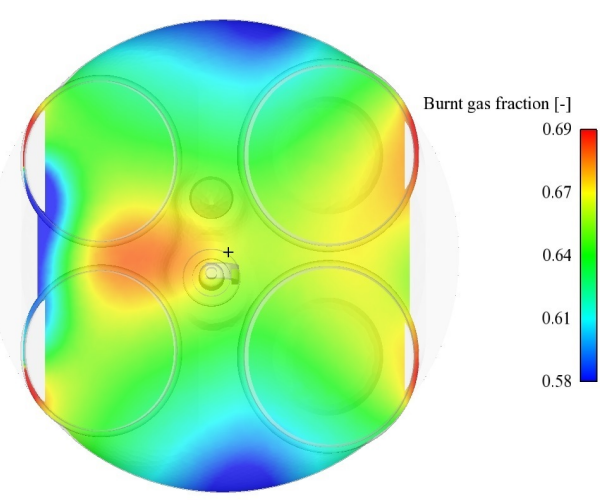

(d) $2 \mathrm{HSR}$

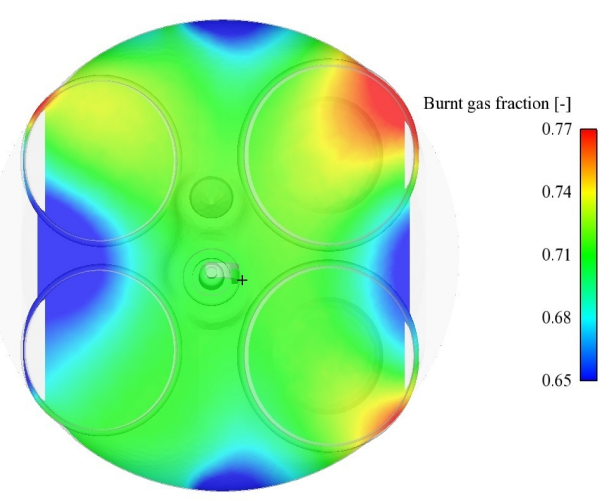

(f) 3BSR

Figure 7. Dilution rate field $20 \mathrm{cad}$ bTDC ('+' signs indicate the location of the first ignition spots)

(temperature and dilution), all of them expressing probability as volume fractions of the combustion chamber.

Values lying outside the display range were brought back to the extreme bins. The consequence is a visual impression of average temperature being above actual average (vertical dashed line in central diagram) because of the low temperature areas near walls. Some apparent visual distortion is also visible for inert gas fraction on some operating conditions with visual average located to a higher value than actual average (horizontal dashed line in central diagram).
Individual temperature distribution was always negatively skewed (longer tail towards low temperatures) because of wall heat losses. Inert gas fraction distribution was less skewed, only really affected at 1500 RPM (negative skew).

For all cases, the most probable conditions (denoted by horizontal and vertical straight lines in (central) joint probability diagram) were a hotter than average temperature and a more diluted than average mixture. Similarly, for all cases except 1HSR, the most probable combination of temperature and dilution lay within the most probable temperature bin and the most probable dilution bin. For case 


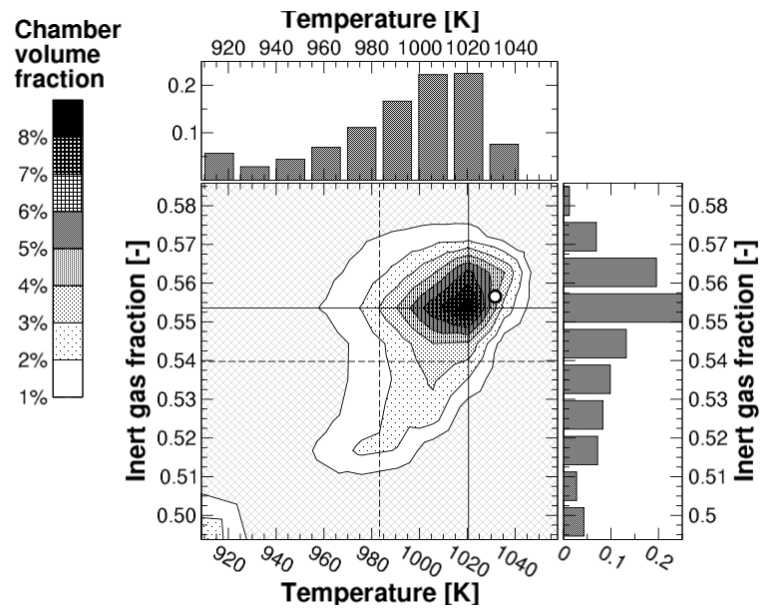

(a) $1 \mathrm{LSR}$

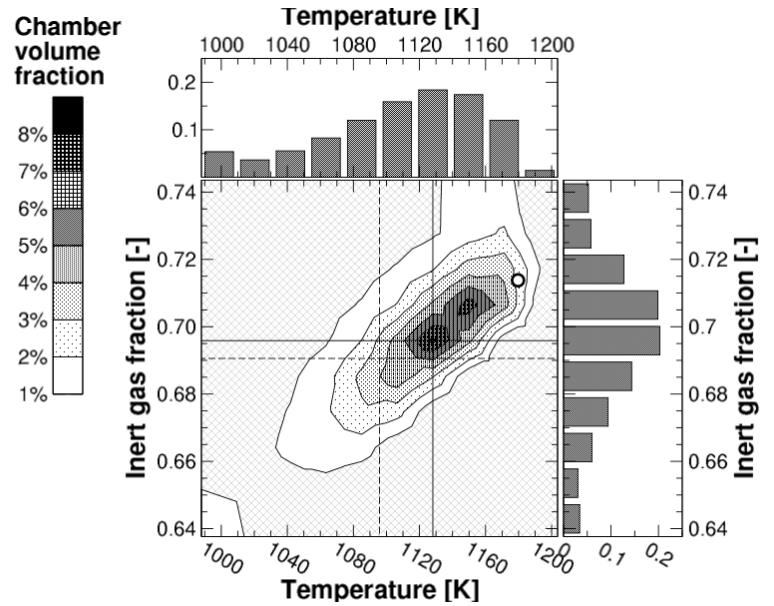

(c) $2 \mathrm{LSR}$

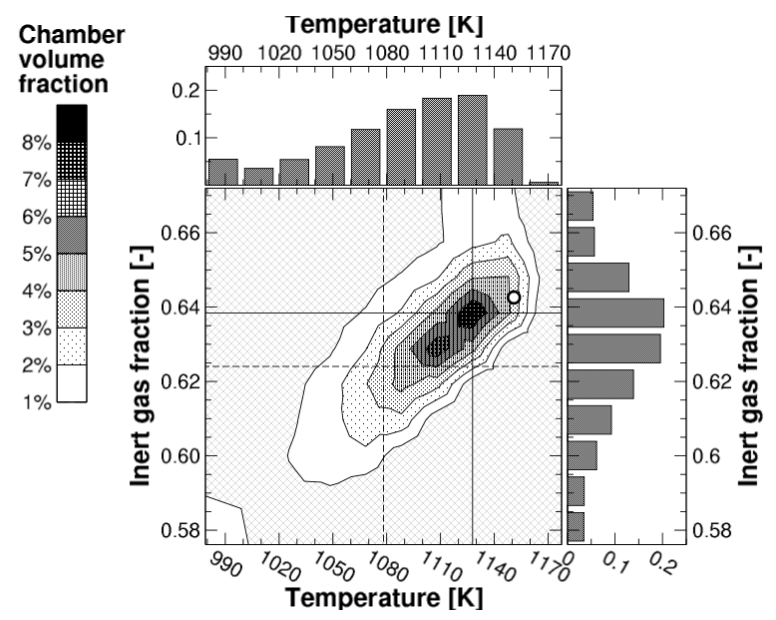

(e) $2 \mathrm{LLR}$

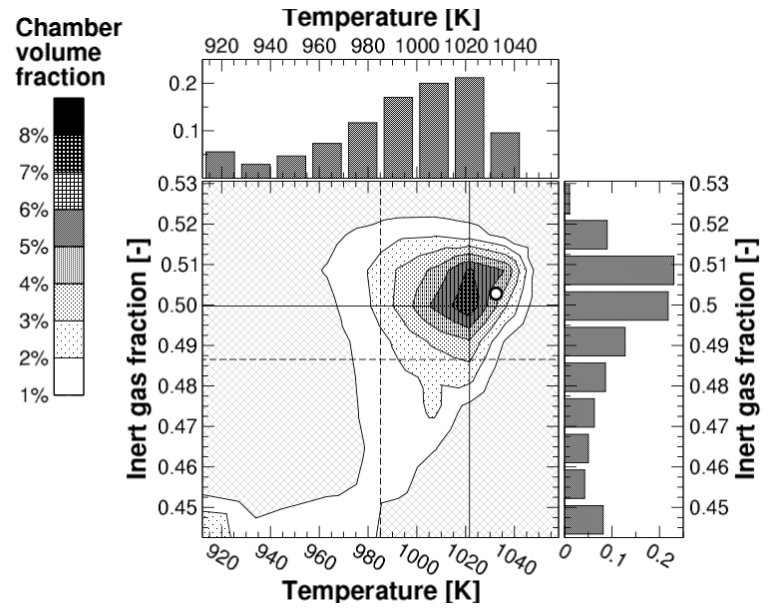

(b) $1 \mathrm{HSR}$

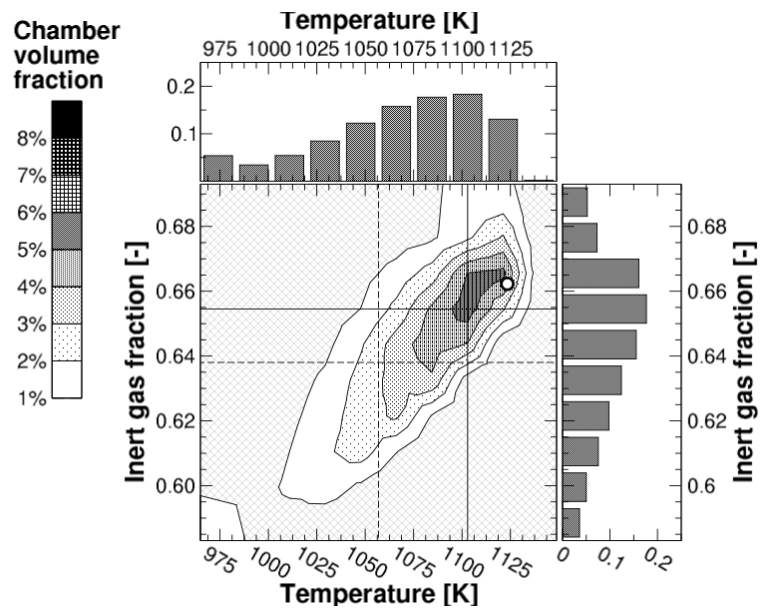

(d) $2 \mathrm{HSR}$

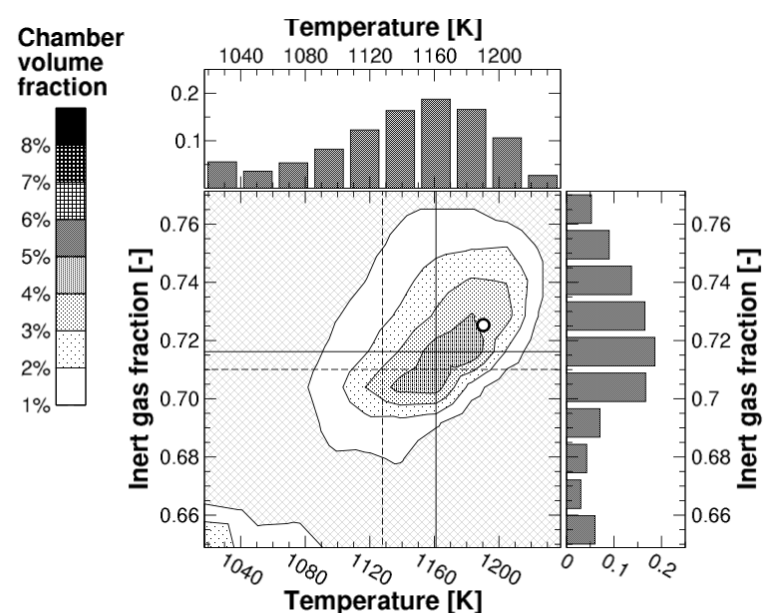

(f) $3 \mathrm{BSR}$

Figure 8. Correlation between local temperature and local dilution rate. Dots indicate the conditions for the first ignition spot.

1HSR, there was a slight shift on dilution axis but it was marginal.

Conditions at first ignition spots (denoted by a dot in joint probability diagram) were always hotter than both average and most probable conditions as well as always more diluted than both average and most probable conditions. However, conditions at first ignition spots were never the hottest nor the most diluted in the combustion chamber.

Conditions at first ignition spots were only marginally more favourable than the most probable condition* denoted

${ }^{*}$ Case 2LSR might be viewed as an exception to this rule but case 2LSR was specific because of the double high probability regions in the joint 
as vertical and horizontal solid lines. On the other hand, they were significantly more favourable than average conditions (denoted as vertical and horizontal dashed lines), explaining the inadequacy of single-zone modelling for such a combustion mode.

Temperature and inert gas fraction distribution were obviously significantly correlated. However, because of heat losses at walls and heat diffusion, a significant spreading in local temperature might be observed for a given inert gas fraction. In the most extreme case (case 3BSR), the most probable dilution level ( $\sim 71.5 \%$ mas) corresponded to a temperature spreading of more than $120 \mathrm{~K}$, i.e. of more than $10 \%$ of the average value. From the chemical kinetics point of view, a difference of $120 \mathrm{~K}$ between two conditions with identical mixture composition is huge, especially when not lying in the intermediate temperature domain. In addition, the hottest conditions never corresponded to the most diluted conditions.

The spatial location of the hottest conditions (Fig. 6) was similar for all operating points: because it was mainly driven by heat losses to the walls, hottest spots were in the middle of the combustion chamber. However, because chemical kinetics were both influenced by local temperature and local dilution, the most reactive conditions (see '+' signs) leading to the earliest heat release were not simply the hottest spots. The analysis of conditions within chamber and the comparison with local conditions at most reactive locations showed that the earliest ignition spots were neither the hottest nor the least diluted ones. The early reaction spots appeared to be a compromise between high local temperature and moderate local dilution but were not simply the most reactive conditions, implicitly emphasizing the existence of at least an additional criterion.

To help understand the interaction between temperature and dilution, we did compute the equivalent auto-ignition delays for conditions encountered at statistical analysis timing. The resulting auto-ignition delays plotted in Fig. 9 confirm that temperature is predominant over dilution rate to define the auto-ignition delay (or mixture reactivity). However, given the dilution rate spreading, there is still a significant effect of local dilution rate. Namely, when looking at the bean-shaped islands of equal chamber volume fraction in Fig. 8, the auto-ignition delay is always the shortest for the East-southeast part of each island. Accordingly, the early ignition spots were always located on the eastern shores of such an island but not necessarily on the eastern shores of the largest island, despite a consequently shorter ignition delay, an early clue that another aspect of mixture formation is important.
The chamber volume fraction for each conditions explained why early reaction spots were not exclusively located on the right side of the largest islands but rather in smaller, more likely regions. The complete combustion process develops with an early ignition spot locally releasing heat and therefore promoting reaction in neighbouring nearly-as-reactive areas. Combustion then progresses through successive auto-ignition promoted by the heat release of just ignited areas. For that process to be successful, two conditions have to be met: (1) neighbouring areas must be reactive enough and (2) locallyreleased heat must be large enough to promote reaction in neighbouring areas despite the dispersive effect of $3 \mathrm{D}$ diffusion and convection. The relative homogeneity of mixture in present conditions ensured that neighbouring areas had a similar reactivity (as opposed to largely stratified conditions that can be obtained with exhaust gas rebreathing strategy ${ }^{7}$ ). However, the reactivity propagation despite diffusion/convection can only be ensured if the reacting spot is large enough to release a sufficient amount of heat to significantly increase local temperature in all neighbouring areas. Consequently, a minimum chamber volume fraction for earlier reaction spot is necessary so that a "reactivity wave" starts propagating. Present results show that a chamber volume fraction between 3 and $4 \%$ is necessary to ensure the self-sustainability of the system. As a consequence, the early reaction spots appear to be the combination of being on the eastern shores of the 3-to-4\% islands of chamber volume fraction.

Given the nature of the temperature field, this statistical location always corresponded to a relatively central spatial location in the combustion chamber. The exact location was a matter of locating the conditions of the eastern island part in the temperature and dilution rate fields.

\section{Discussion}

Present results highlight the central influence of temperature stratification within the cylinder on the complete combustion process in CAI engines operated in NVO mode. Changing operating conditions affects mixture formation so that various types of temperature stratification might be obtained. Comparing the results for selected operating conditions, one might conclude on the relative influence of engine speed, engine load and mixture leaning on mixture formation and therefore on combustion progress.

probability diagram. If the first ignition spots were compared to the second most probable conditions, then the general conclusion still held. 


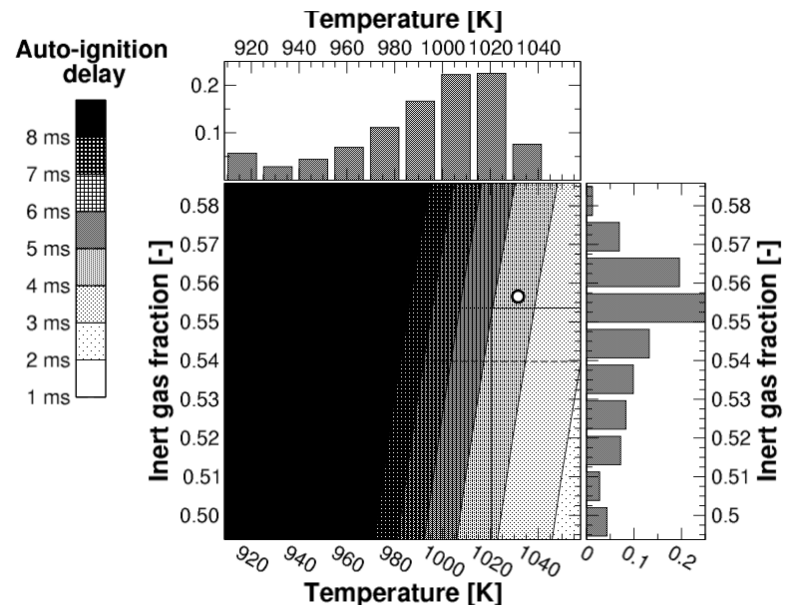

(a) $1 \mathrm{LSR}$

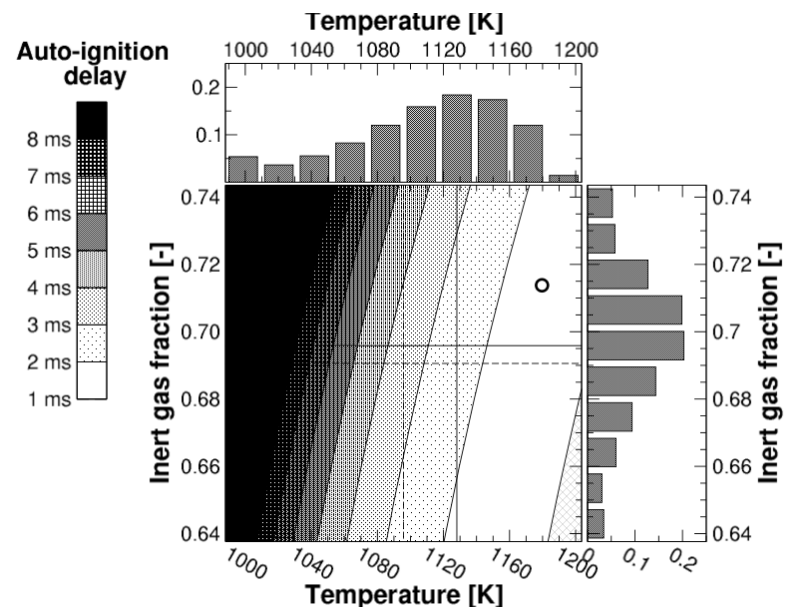

(c) $2 \mathrm{LSR}$

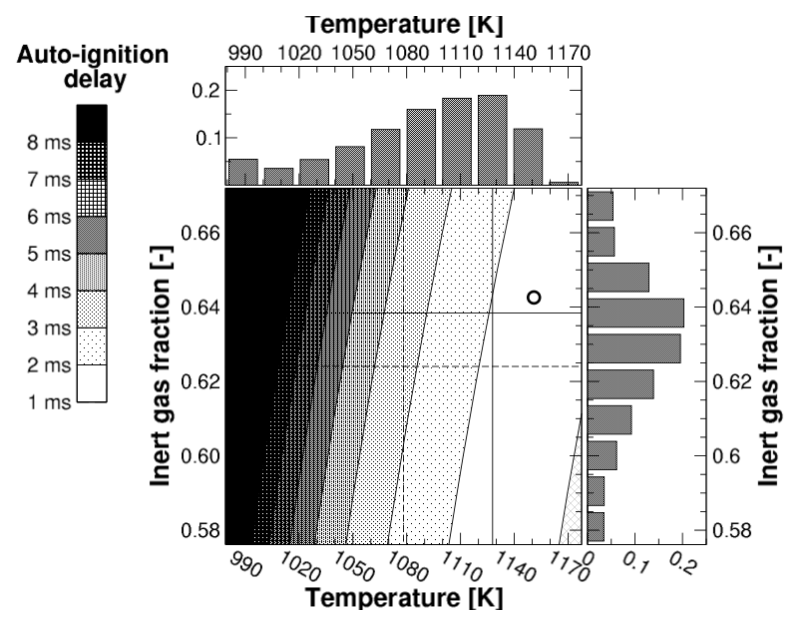

(e) $2 \mathrm{LLR}$

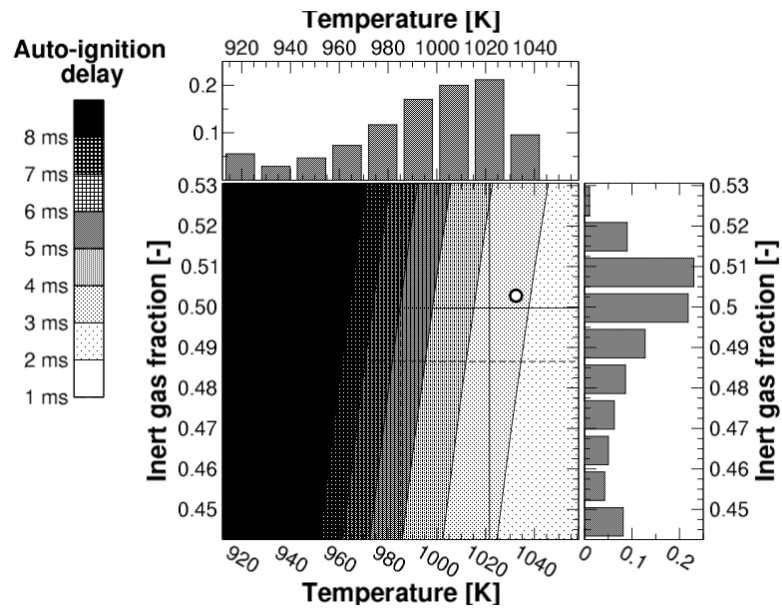

(b) $1 \mathrm{HSR}$

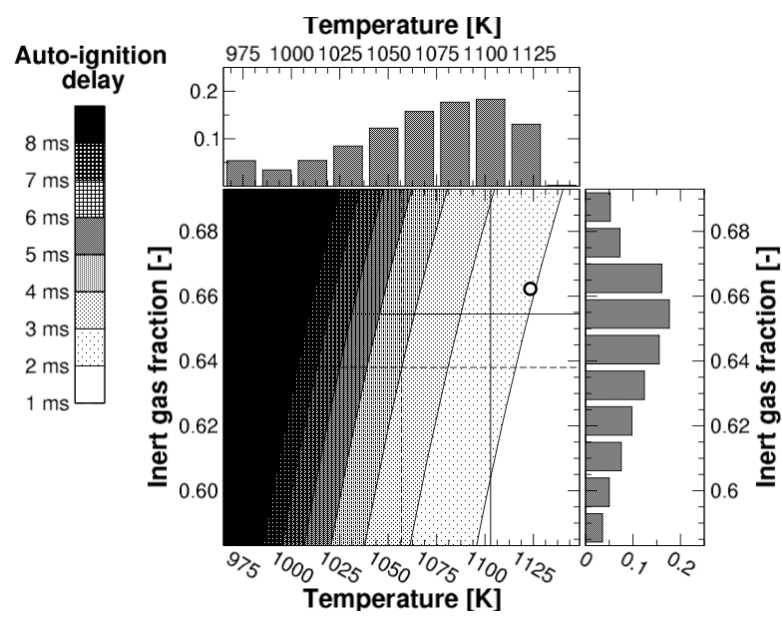

(d) $2 \mathrm{HSR}$

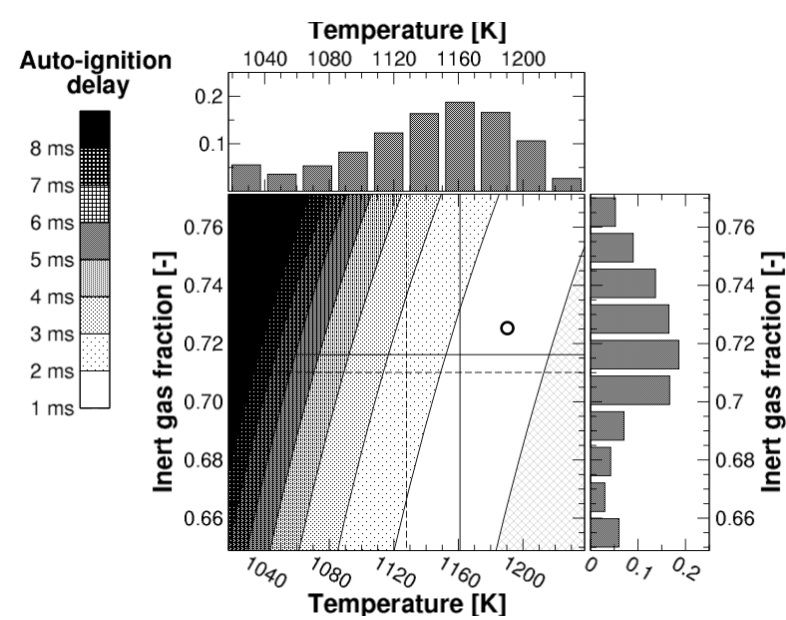

(f) $3 \mathrm{BSR}$

Figure 9. Combined influence of local temperature and local dilution rate on auto-ignition delays according to the proposed revised iso-octane submechanism. Dots indicate the conditions for the first ignition spot.

For considered conditions, mixture leaning has the weakest influence because of its restricted effect on flow motion and mixture formation. Mixture leaning intensity in CAI engines is always limited ${ }^{42}$, only slightly modifying air mass flow rate through valves compared to stoichiometric operation. As a consequence, mixture formation is mostly unchanged, both on air/fuel mixture homogeneity and temperature stratification sides. Combustion timing differences exclusively result from the changes in mean in-cylinder fuel/air equivalence ratio, dilution rate and temperature. Comparison of points $2 \mathrm{LSR}$ and 2LLR confirms this analysis: the statistical diagrams in 
Fig. 8 have identical shapes with a scale shift of $30 K$ towards lower temperatures and a scale shift of $6 \%$ towards lower dilution rate for the lean operating point.

Engine load has slightly more influence on the local in-cylinder conditions, even if a first sight at computed fields (Figs. 6 and 7) does not outline obvious differences. The main effect of changing load remains the alteration of mean in-cylinder conditions. Be it at $1500 R P M$ or at $2500 R P M$, moving from the operating map highest load to the lowest load implies an increase of $5 \%$ in local dilution rate. Temperature is, however, differently affected depending on engine speed: unchanged at $1500 K$, while increased by $50 \mathrm{~K}$ at lowest load at $2500 \mathrm{~K}$. Despite the change in mean incylinder conditions with engine load, no significant change in joint diagram shape is observed. This confirms that engine load has only a secondary effect on the detail of local mixture stratification, while it does have a first order influence on mean in-cylinder conditions.

Engine speed is the first order parameter for mixture stratification as is obvious from comparison of diagrams for points 1LSR, 2LSR, and 3BSR (or alternatively 1HSR, 2HSR, and 3BSR) in Fig. 8 or from comparison of actual temperature and dilution rate fields in Figs. 6 and 7. Increasing engine speed enlarges the stratification along both dilution rate and temperature axes because of the restriction in time available for mixing. To better outline the increase in stratification, Fig. 10 depicts iso-contours for $1 \%$ and $4 \%$ chamber volume fractions for all 3 engine speeds, grouped by load classes and expressed as variations with respect to average in-cylinder conditions. Fig. 10 confirms that mixture stratification increases (in absolute value) with engine speed, both along temperature and dilution axes. Comparison of Figs. 10(a) and 10(b) further outlines the similarity of stratification when changing load (result at $3500 R P M$ can be used as a reference for comparison as it is identical on both sides), confirming the predominance of engine speed on the stratification process.

Present results indicate that influence of engine speed and load on CAI combustion can be split into two parts: (1) engine speed and load affect mean in-cylinder conditions while (2) engine speed only significantly affects mixture stratification (species and temperature). These two aspects explain the intrinsic limitations of the CAI operating map. The change in mean in-cylinder conditions explains the low load and low speed limits of the operating map: for such conditions, mixture becomes to unreactive to sustain combustion, either through excessive dilution when reducing load, or through too cool a mixture when reducing engine speed. Such effects combine in the worst case scenario that is nearing idling conditions. On the other end, increasing stratification at higher engine speeds tends to worsen combustion stability and cycle efficiency because the coolest part of the combustion chamber hardly or lately burn, so that the CAI operating map also has an intrinsic limit towards the highest engine speeds.

Finally, modelling of CAI operation with two variants of the same mechanism outlined the significant influence of kinetics in the transition area between intermediate and high temperature regions. Precision for alkane kinetics in such conditions is vital as, through their specific behaviour, they dominate the reactivity of the complete mixture by favouring the chemical runaway of other compounds.

\section{Conclusions}

The modelling of operating points across the complete operation map of a CAI engine using the NVO strategy demonstrates that the global combustion progress is insensitive to operating conditions. First ignition spots are always defined by high temperature conditions with significant statistical probability, and relatively low dilution rate for such a temperature. As heat losses to the walls are intense in CAI engines due to the high mean in-cylinder temperature during most of the engine cycle, such high temperature conditions are always located near the centre of the combustion chamber. From that point, combustion propagates towards walls through successive auto-ignitions induced by heat release in neighbouring areas.

Changing the operating conditions mainly affects the mean in-cylinder conditions, while only a significant change in engine speed can act on mixture stratification that controls the location of the first ignition spot. Nevertheless, changing the mean in-cylinder conditions on its own can have a significant effect on the outcome of stratification influence. If mean in-cylinder conditions lie in the intermediate temperature domain, the weaker influence of temperature on auto-ignition delays restricts the influence of stratification. On the other hand, if mean in-cylinder conditions lie in the high temperature domain, sensitivity to temperature is more important and stratification becomes very influent.

The strong interaction between local mixture conditions and fuel kinetics, that defines the limits of the CAI operating map, imposes to correctly capture both. Present results highlight that latest computational approaches are able tackle this issue, provided that our knowledge of fuel kinetics in the intermediate temperature domain further progresses. $D e$ facto even for some of the best known paraffins (iso-octane in the present case), there is still no consensus on reactivity 


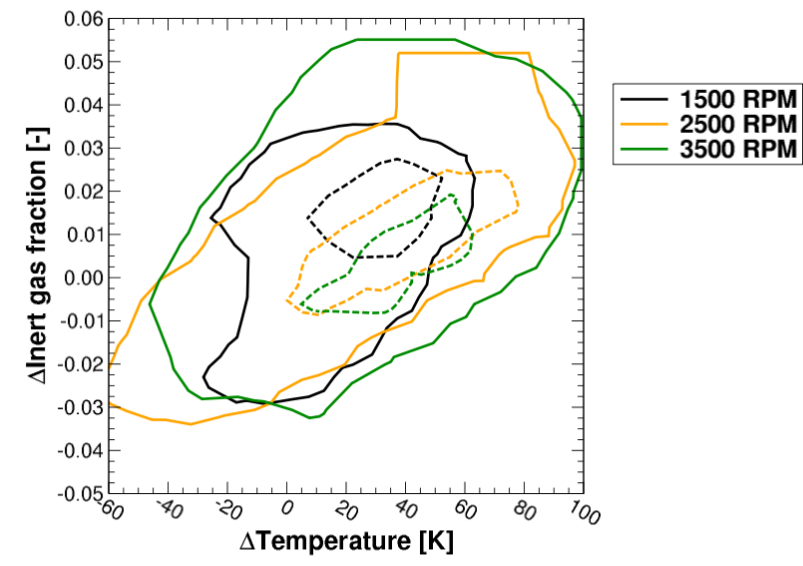

(a) Low loads

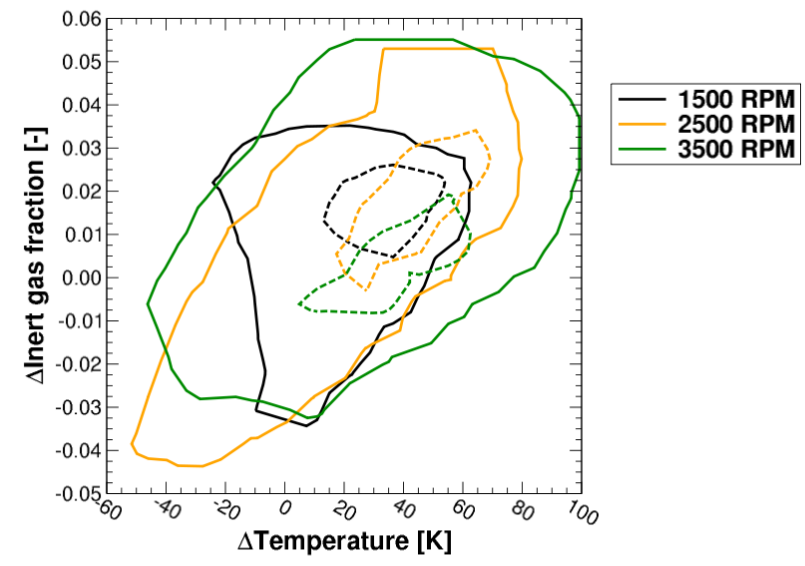

(b) High loads

Figure 10. Comparison of temperature-to-dilution correlations for different engine speeds. Left diagram compares low load test cases 1LSR, 2LSR, and 3BSR. Right diagram compares high load test cases 1HSR, 2HSR, and 3BSR. Solid lines indicate iso-contours for $1 \%$ of chamber volume fraction. Dashed lines indicate iso-contours for $4 \%$ of chamber volume fraction.

in the 800 to $1200 \mathrm{~K}$ range that is so important to engine operation, as highlighted by present results comparing two different reduced mechanisms. The lack of NTC behaviour for iso-octane has to be properly reproduced by kinetics to accurately predict the CAI combustion sensitivity to operating conditions. In the wider context of in-engine autoignition, such a conclusion might lead to reconsider the known influence of $i$ so-octane chemistry on engine knock.

The present numerical results provide a complete view on mixture state, allowing to distinct the effects of mean in-cylinder conditions from the influence of mixture stratification. This gives the opportunity to better understand the intrinsic operating map limitations towards the lower and higher loads. The low load - low speed limit of the CAI operating map is characterised by low mean in-cylinder temperatures, high mean in-cylinder dilution rates and restricted mixture stratification. Mean in-cylinder conditions are adverse to auto-ignition and the lack of marked stratification prevents from having locally more favourable conditions that initiate the cascading combustion process, hence the encountered ignition difficulties. In contrast, the high load - high speed limit has excessive stratification, so that a relatively early combustion is required to convert all the fuel, including the fraction located in the coolest areas. However, early combustion increases the combustionrelated noise. Simultaneously avoiding large emissions and excessive combustion noise therefore restricts the extent of the operating map on the high load side.

\section{References}

1. Richter M, Engström J, Franke A et al. The influence of charge inhomogeneity on the HCCI combustion process. SAE Paper 2000-01-2868 2000;

2. Hultqvist A, Christensen M, Johansson B et al. The HCCI combustion process in a single cycle speed fuel tracer LIF and chemiluminescence imaging. SAE Paper 2002-01-0424 2002;

3. Babajimopoulos A, Lavoie GA and Assanis DN. Numerical modeling of the effects of temperature and composition stratification on HCCI combustion for high levels of residual gas fraction. SAE NA Paper 2003-01-41 2003; .

4. Koopmans L, Wallesten J, Ogink R et al. Location of the first auto-ignition sites for two heci systems in a direct injection engine. SAE Paper 2004-01-0564 2004; .

5. Mori S, Lang O, Salber $W$ et al. Type analysis of EGR-strategies for Controlled Auto-Ignition (CAI) by using numerical simulations and optical measurements. SAE Paper 2006-01-0630 2006; .

6. Dec JE, Hwang W and Sjöberg M. An investigation of thermal stratification in hcci engines using chemiluminescence imaging. SAE Paper 2006-01-1518 2006; .

7. Knop V, Thirouard B and Chérel J. Influence of the local mixture characteristics on the combustion process in a cai engine. SAE Paper 2008-01-1671 2008; .

8. Adomeit P, Sehr A, Weinowski R et al. Operation strategies for controlled auto ignition gasoline engines. SAE Paper 2009-010300 2009;

9. Pera $\mathrm{C}$ and Knop V. Methodology to define gasoline surrogates dedicated to auto-ignition in engines. Fuel 2012; 96: 59-69. 
10. Knop V, Pera C and Duffour F. Validation of a ternary gasoline surrogate in a CAI engine. Combust Flame 2013; 160: 20672082.

11. Andrae JCG. Comprehensive chemical kinetic modeling of toluene reference fuels oxidation. Fuel 2013; 107: 740-748.

12. Knop V, de Francqueville L, Duffour F et al. Influence of the valve-lift strategy in a cai engine using exhaust gas re-breathing part 2: Optical diagnostics and $3 \mathrm{~d}$ cfd results. SAE Paper 2009 01-0495 2009; .

13. Nakano M, Mandokoro Y, Kubo S et al. Effects of exhaust gas recirculation in homogeneous charge compression ignition engines. Int J Engine Res 2000; 1: 269-279.

14. Dec JE. A computational study of the effects of low fuel loading and egr on heat release rates and combustion limits in hcci engines. SAE Paper 2002-01-1309 2002; .

15. Naik CV, Pitz WJ, Westbrook CK et al. Detailed chemical kinetic modelling of surrogate fuels for gasoline and application to an heci engine. SAE Paper 2005-01-3741 2005;

16. Sjöberg $M$ and Dec JE. Comparing late-cycle autoignition stability for single- and two-stage ignition fuels in hcci engines. Proc Combust Inst 2007; 31: 2895-2902.

17. Andrae J, Brinck T and Kalghatgi G. Hcci experiments with toluene reference fuels modeled by a semidetailed chemical kinetic model. Combust Flame 2008; 155: 696-712.

18. Andrae $\mathrm{J}$ and Head R. Hcci experiments with gasoline surrogate fuels modeled by a semidetailed chemical kinetic model. Combust Flame 2009; 156: 842-851.

19. Morgan N, Smallbone A, Bhave A et al. Mapping surrogate gasoline compositions into ron/mon space. Combust Flame 2010; 157: 1122-1131.

20. Mehl M, Pitz W, Sarathy M et al. Detailed kinetic modeling of conventional gasoline at highly boosted conditions and the associated intermediate temperature heat release. SAE Paper 2012-01-1109 2012; .

21. Aceves SM, Flowers DL, Westbrook CK et al. A multi-zone model for prediction of hcci combustion and emissions. SAE Paper 2000-01-0327 2000; .

22. Babajimopoulos A, Assanis D and Fiveland SB. An approach for modeling the effects of gas exchange processes on hcci combustion and its application in evaluating variable valve timing control strategies. SAE Paper 2002-01-2829 2002; .

23. Puduppakkam KV, Liang L, Naik CV et al. Combustion and emissions modeling of a gasoline hcci engine using model fuels. SAE Paper 2009-01-0669 2009; .

24. Sjöberg M, Dec JE and Cernansky NP. Potential of thermal stratification and combustion retard for reducing pressure-rise rates in HCCI engines, based on multi-zone modeling and experiments. SAE Paper 2005-01-0113 2005; .
25. Anderlohr JM, Bounaceur R, Pirès da Cruz A et al. Modelling of autoignition and no sensitization for the oxidation of ic engine surrogate fuels. Combust Flame 2009; 156: 505-521.

26. Mehl M, Curran HJ, Pitz WJ et al. Chemical kinetic modeling of component mixtures relevant to gasoline. European Combust Meeting 2009; .

27. Sakai Y, Miyoshi A, Koshi M et al. A kinetic modeling study on the oxidation of primary reference fuel-toluene mixtures including cross reactions between aromatics and aliphatics. Proc Combust Inst 2009; 32: 411-418.

28. Cancino LR, Fikri M, Oliveira AAM et al. Ignition delay times of ethanol-containing multi-component gasoline surrogates: Shock-tube experiments and detailed modeling. Fuel 2011; 90 : $1238-1244$.

29. Vandersickel A, Hartmann M, Vogel K et al. The autoignition of practical fuels at hcci conditions: High-pressure shock tube experiments and phenomenological modeling. Fuel 2012; 93: 492-501.

30. Liu $\mathrm{H}$, Zhang $\mathrm{P}, \mathrm{Li} \mathrm{Z}$ et al. Effects of temperature inhomogeneities on the HCCI combustion in an optical engine. Applied Thermal Engineering 2011; 31: 2549-2555.

31. Maas U and Pope SB. Simplifying chemical kinetics: Intrinsic low-dimensional manifolds in composition space. Combust Flame 1992; 88: 239-264.

32. Gicquel O, Darabiha $\mathrm{N}$ and Thevenin D. Laminar premixed hydrogen/air counterflow flame simulations using flame prolongation of ildm with differential diffusion. Proc Combust Inst 2000; 28: 1901-1908.

33. van Oijen JA, Lammers FA and de Goey LPH. Modeling of complex premixed burner systems by using flamelet-generated manifolds. Combust Flame 2001; 127: 2124-2134.

34. Pirès da Cruz A. Three-dimensional modeling of self-ignition in HCCI and conventional diesel engines. Combust Sci Technol 2004; 176: 867-887.

35. Colin O, Pirès da Cruz A and Jay S. Detailed chemistry based auto-ignition model including low temperature phenomena applied to 3-D engine calculations. Proc Combust Inst 2005; 30: 2649-2656.

36. Pera C, Colin O and Jay S. Development of a FPI detailed chemistry tabulation methodology for internal combustion engines. Oil Gas Sci Technol 2009; 64: 243-258.

37. Knop V, Michel JB and Colin O. On the use of a tabulation approach to model auto-ignition during flame propagation in SI engines. Appl Energy 2011; 88: 4968-4979.

38. Fieweger K, Blumenthal R and Adomeit G. Self-ignition of S.I. engine model fuels: A shock tube investigation at high pressure. Combust Flame 1997; 109: 599-619.

39. Sakai Y, Miyoshi A, Koshi M et al. Shock tube ignition measurements of iso-octane/air and toluene/air at high 
pressures. Proc Combust Inst 2005; 30: 1175-1182.

40. Shen HS, Vanderover J and Oehlschlaeger MA. A shock tube study of iso-octane ignition at elevated pressures: The influence of diluent gases. Combust Flame 2008; 155: 739-755.

41. Hartmann M, Gushterova I, Fikri M et al. Auto-ignition of toluene-doped n-heptane and iso-octane/air mixtures: Highpressure shock-tube experiments and kinetics modeling. Combust Flame 2011; 158: 172-178.

42. Duffour F, Knop V, Vangraefschèpe F et al. Quantifying benefits of dual cam phasers, lean mixture and egr on the operating range and fuel economy of a pfi nvo cai engine. $S A E$ Paper 2010-01-0844 2010; .

43. Curran HJ, Pitz WJ, Westbrook CK et al. Oxidation of automotive primary reference fuels at elevated pressures. Proc Combust Inst 1998; 27: 379-387.

44. Curran HJ, Gaffuri P, Pitz WJ et al. A comprehensive modeling study of iso-octane oxidation. Combust Flame 2002; 129: 253280.

45. Tanaka S, Ayala F and Keck JC. A reduced chemical kinetic model for HCCI combustion of primary reference fuels in a rapid compression machine. Combust Flame 2003; 133: 467481.

46. Jia M and Xie M. A chemical kinetics model of iso-octane oxidation for HCCI engines. Fuel 2006; 85: 2593-2604.

47. http://www.lmsintl.com/ LMS-Imagine-Lab-AMESim.

48. Duffour F, Vangraefschèpe F, Knop V et al. Influence of the valve-lift strategy in a cai engine using exhaust gas re-breathing part 1: Experimental results and 0d analysis. SAE Paper 200901-0299 2009; .

49. Woschni G. Universally applicable equation for the instantaneous heat transfer coefficient in the internal combustion engine. SAE Paper 670931 1967; .

50. Wiebe II. Semi-empirical expression for combustion rate in engines. Proceedings of Conference on Piston Engines, USSR Academy of Sciences 1956; : 186-191.

51. Bohbot J, Gillet N and Benkenida A. IFP-C3D: an unstructured parallel solver for reactive compressible gas flow with spray. Oil Gas Sci Technol 2009; 64: 309-335.

52. Han $\mathrm{Z}$ and Reitz RD. Turbulence modeling of internal combustion engines using RNG k- $\epsilon$ models. Combustion Science and Technology 1995; 106: 267-295.

53. Kays WM and Crawford ME. Convective Heat and Mass Transfer. Third ed. McGraw-Hill, 1994.

54. Thirouard B and Chérel J. Nature of cai combustion and air/fuel ratio stratification effects. Oil Gas Sci Technol 2006; 61: 95-119.

55. Li Y, Zhao H and Brouzos N. Cai combustion with methanol and ethanol in an air-assisted direct injection si engine. SAE

Paper 2008-01-1673 2008; .

56. Gottschalk W, Magnor O, Schultalbers M et al. Gasoline hcci/cai on a four-cylinder test bench and vehicle engine results and conclusions for the next investigation steps. SAE Paper 2010-01-1488 2010; .

57. Cao L, Zhao H, Jiang $X$ et al. Effects of intake valve timing on premixed gasoline engine with cai combustion. SAE Paper 2004-01-2953 2004; .

58. Knop V and Mattioli L. An analysis of limits for part load efficiency improvement with vva devices. Energy Conversion and Management 2015; 105: 1006-1016.

\section{Supplemental material \\ Supplemental material}



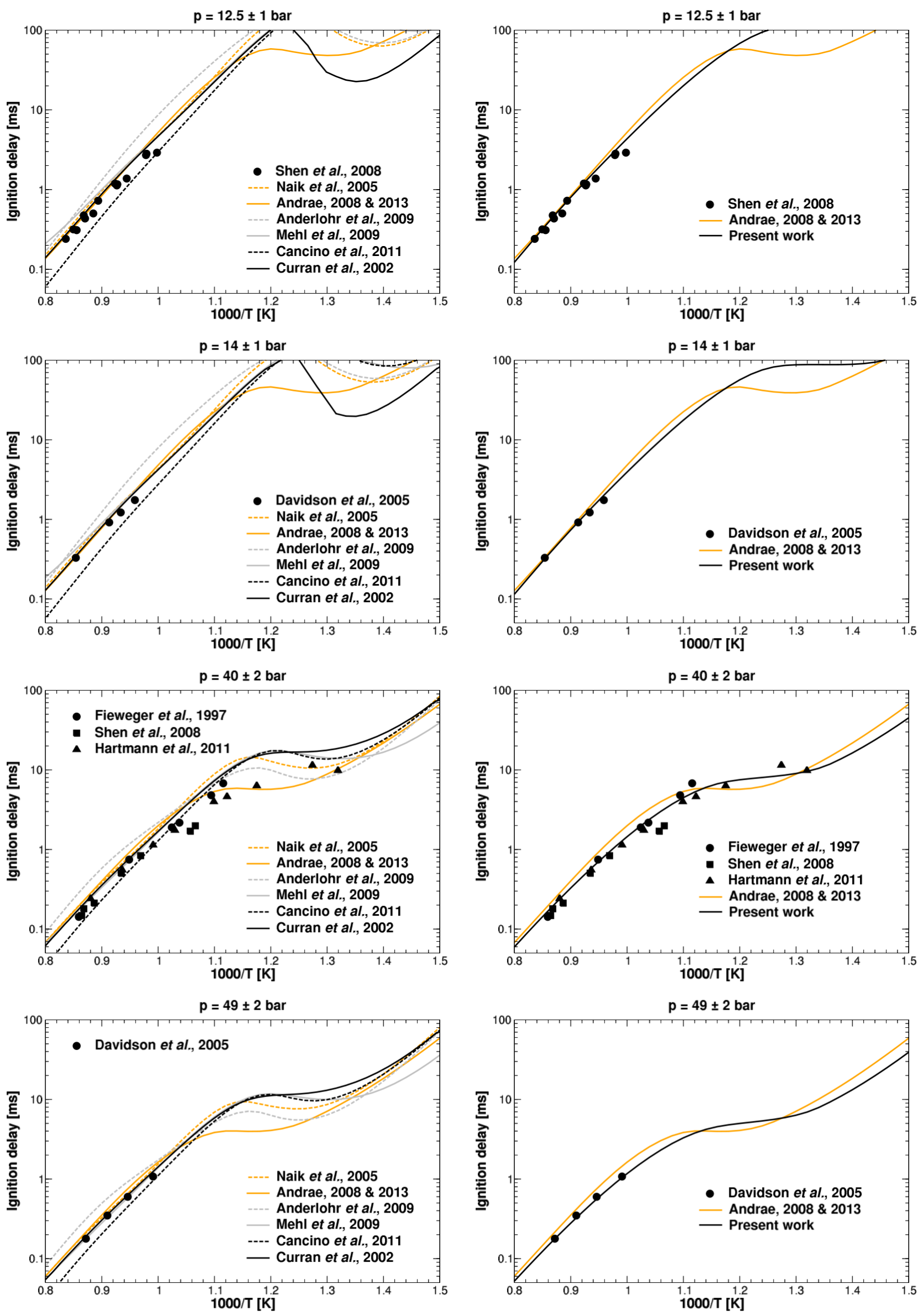

Figure 11. Comparison of auto-ignition delay measurements (symbols) with numerical predictions (lines) for lean iso-octane/air mixtures $(\phi=0.5)$. Left: existing mechanisms. Right: revised mechanism. 

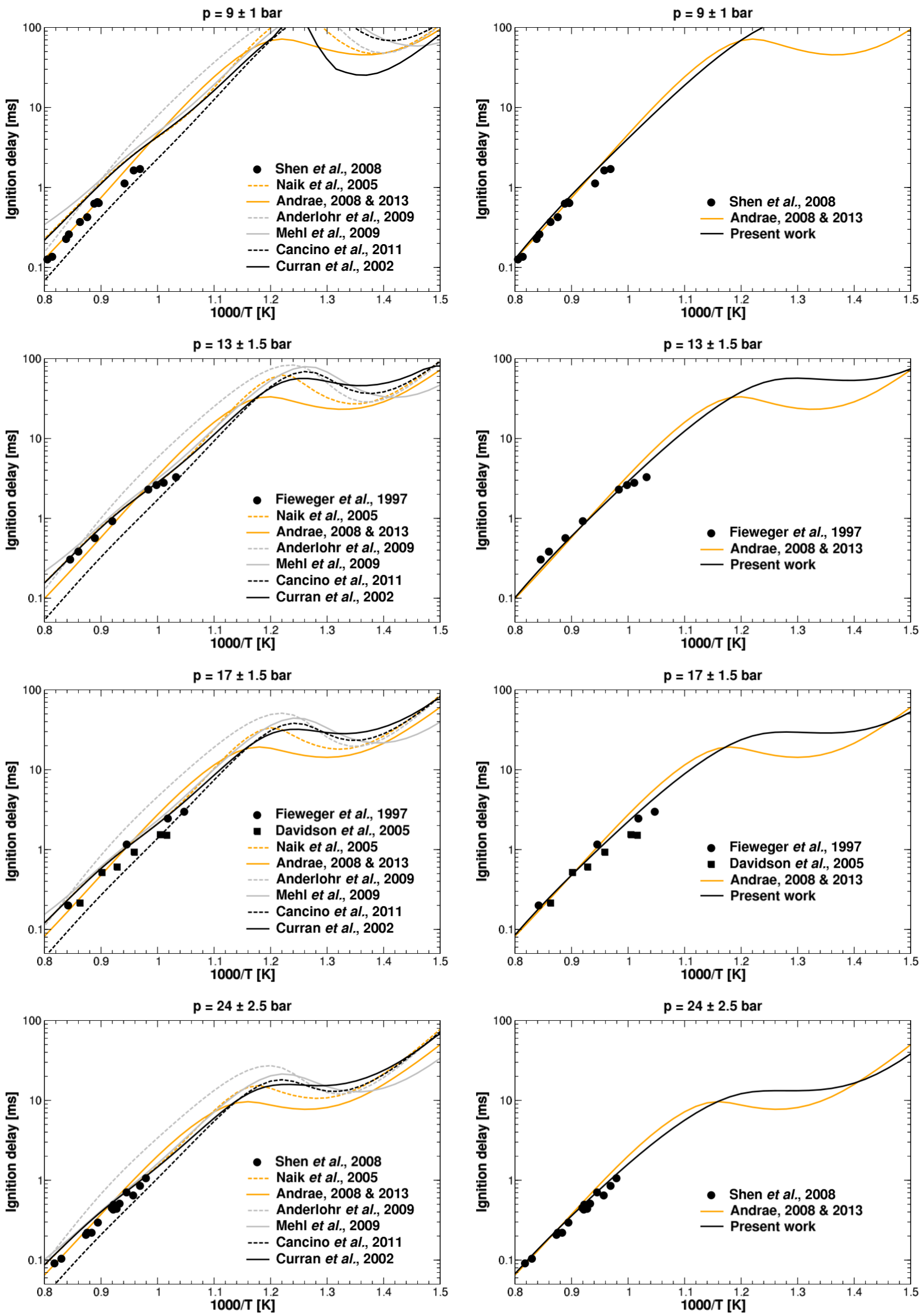

Figure 12. Comparison of auto-ignition delay measurements (symbols) with numerical predictions (lines) for stoichiometric iso-octane/air mixtures at lower pressures. Left: existing mechanisms. Right: revised mechanism. 

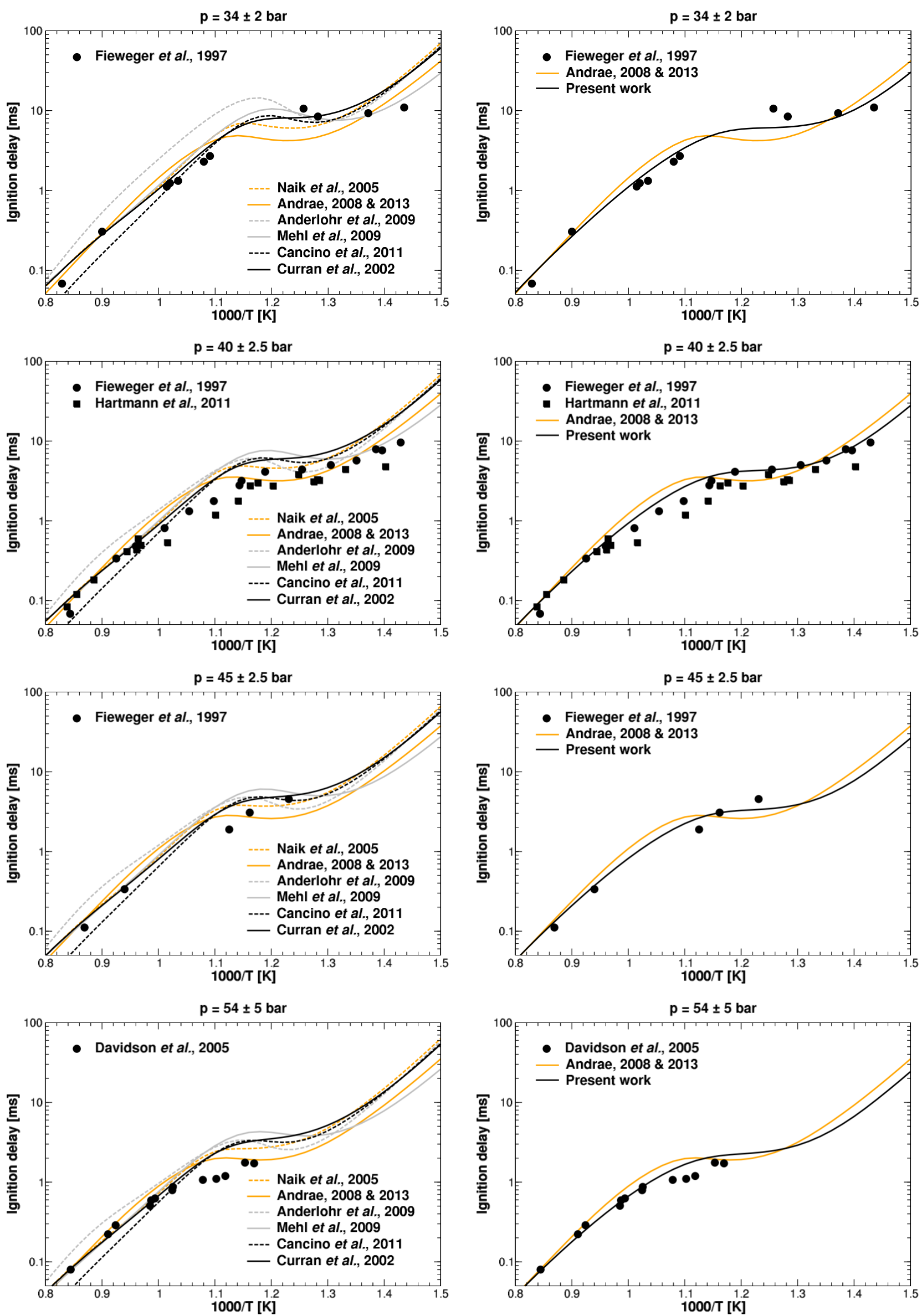

Figure 13. Comparison of auto-ignition delay measurements (symbols) with numerical predictions (lines) for stoichiometric iso-octane/air mixtures at higher pressures. Left: existing mechanisms. Right: revised mechanism. 